\title{
A Multi-pronged Screening Approach Targeting Inhibition of ETV6 PNT Domain Polymerization
}

\author{
Chloe A. N. Gerak ${ }^{1}$, Si Miao Zhang ${ }^{1}$, Aruna D. Balgi ${ }^{1}$, Ivan J. Sadowski ${ }^{1}$, \\ Richard B. Sessions ${ }^{2}$, Lawrence P. McIntosh ${ }^{1,3}$, Michel Roberge ${ }^{1}$
}

${ }^{1}$ Department of Biochemistry and Molecular Biology, University of British Columbia, Vancouver, BC, Canada

${ }^{2}$ School of Biochemistry, University of Bristol, Bristol, United Kingdom

${ }^{3}$ Department of Chemistry, University of British Columbia, Vancouver, BC, Canada

Corresponding Author Michel Roberge, Department of Biochemistry and Molecular

Biology, University of British Columbia, Vancouver, BC, Canada.

Email: michelr@mail.ubc.ca

\section{Keywords}

ETS transcription factor, SAM domain, protein-protein interaction, protein fragment complementation assay, virtual screening 


\begin{abstract}
ETV6 is an ETS family transcriptional repressor for which head-to-tail polymerization of its PNT domain facilitates cooperative binding to DNA by its ETS domain. Chromosomal translocations frequently fuse the ETV6 PNT domain to one of several protein tyrosine kinases. The resulting chimeric oncoproteins undergo ligand-independent self-association, autophosphorylation, and aberrant stimulation of downstream signaling pathways leading to a variety of cancers. Currently, no small molecules inhibitors of ETV6 PNT domain polymerization are known and no assays targeting PNT domain polymerization have been described. In this study, we developed complementary experimental and computational approaches for identifying such inhibitory compounds. One mammalian cellular approach utilized a mutant PNT domain heterodimer system covalently attached to split Gaussia luciferase fragments. In this protein fragment complementation assay, inhibition of PNT domain heterodimerization reduces luminescence. A yeast assay took advantage of activation of the reporter HIS3 gene upon heterodimerization of mutant PNT domains fused to DNA-binding and transactivation domains. In this two-hybrid screen, inhibition of PNT domain heterodimerization prevents cell growth in medium lacking histidine. The Bristol University Docking Engine (BUDE) was used to identify virtual ligands from the ZINC8 library predicted to bind the PNT domain polymerization interfaces. Over 75 hits from these three assays were tested by NMR spectroscopy for binding to the purified ETV6 PNT domain. Although none were found to bind, lessons learned from this study may facilitate future approaches for developing therapeutics that act against ETV6 oncoproteins by disrupting PNT domain polymerization.
\end{abstract}




\section{Introduction}

The ETV6 gene, known also as TEL (translocation ETS leukemia), encodes an ETS family transcriptional repressor with roles in embryonic development and hematopoietic regulation. . $^{1,3}$ This gene is frequently rearranged in chromosomal translocations to form fusion oncoproteins linked with various cancers including leukemias, lymphomas, carcinomas, and sarcomas. ${ }^{4-6}$ Over 40 different such translocations are known to exist, including those leading to the ETV6-PDGFRB, ETV6-NTRK3, ETV6-ABL1/2, and ETV6-JAK2 gene fusions. ${ }^{4,6-9}$

ETV6 is a modular protein composed of an N-terminal self-associating PNT (or SAM) domain, a disordered central region reported to interact with co-repressors, and a C-terminal DNAbinding ETS domain. ${ }^{10,11}$ Most of the oncogenic ETV6 translocations lead to chimeras with the PNT domain fused to the protein tyrosine kinase (PTK) domain from a receptor tyrosine kinase. Crucial to their oncogenic properties is the propensity of the ETV6 PNT domain to tightly selfassociate into an open-ended, left-handed helical polymer via head-to-tail binding of two relatively flat, hydrophobic interfaces. ${ }^{12-14}$ PNT domain polymerization enables ligand-independent autophosphorylation and activation of the PTK domain. This stimulates downstream cellular pathways, such as the PI3K/Akt and Ras-MAPK signaling cascades, and ultimately causes cellular transformation. ${ }^{15-17}$

One well-characterized ETV6 translocation encodes the PNT domain fused to the PTK domain of neurotrophin tyrosine receptor kinase-3 (NTRK3). The resulting protein, named EN (ETV6-NTRK3), displays oncogenic properties including phenotypic transformation and soft agar colony formation of several experimental cell lines, as well as tumor formation in nude mice. ${ }^{6,17}$ The ETV6 PNT domain polymerization interfaces, called the mid-loop (ML) and end-helix (EH) surfaces, have hydrophobic cores surrounded by charged residues. ${ }^{18}$ The mutation of one of two 
key hydrophobic residues to a charged residue (A93D on the ML surface, or V112E or V112R on the EH surface, according to the human ETV6 numbering) disrupts polymerization. ${ }^{14,18}$ Introduction of these mutations into EN expressing cell lines prevents EN polymerization, PTK activation and cellular transformation. ${ }^{13}$ Similarly, mutation of the K99-D101 charge pair bridging the PNT domain interfaces weakens polymerization and inhibits the transformation activity of EN in NIH3T3 cells. ${ }^{19}$ Co-expression of an isolated PNT domain also has a dominant negative effect, preventing cellular transformation. ${ }^{13}$ Together, these studies indicate inhibition of PNT domain polymerization as a viable therapeutic strategy against cancers driven by ETV6 chromosomal translocations.

We hypothesized that small molecules that prevent the self-association, and hence oncogenic properties, of ETV6 chimeras containing the PNT domain might serve as a potential broad spectrum therapy against many ETV6 PNT domain-containing oncoproteins and avoid toxicities associated with perturbing the normal activities of receptor PTKs. Furthermore, although approximately one-third of the 28 ETS transcription factor family members in humans possess a PNT domain, only ETV6 and likely ETV7 polymerize. ${ }^{20-22}$ Thus a molecule that selectively inhibits ETV6 PNT domain polymerization may have few side effects.

Protein-protein interactions (PPIs) are challenging to disrupt, and hence we undertook complementary cellular and virtual screening strategies in the attempt to discover inhibitors of ETV6 PNT domain polymerization. Central to our approach is the use of PNT domains with monomerizing mutations in the $\mathrm{EH}$ or ML surfaces that can still associate with low $\mathrm{nM}$ affinity through their remaining complementary wild-type interfaces. ${ }^{14,18}$ The soluble "heterodimer" serves as a model of the insoluble polymer, opening the door for in vitro and in vivo screens. In brief, both a mammalian cell-based assay utilizing a protein-fragment complementation approach with 
split Gaussia luciferase ${ }^{23}$ (Fig. 1A) and a yeast two-hybrid assay ${ }^{24}$ (Fig. 1B) were developed and used to screen chemical libraries for potential inhibitors. In parallel, large scale virtual screening using the Bristol University Docking Engine (BUDE) was performed to identify theoretical compounds that might bind to the PNT domain polymerization interfaces. ${ }^{25,26}$ Subsequently, candidate compounds were tested for inhibitory effects in cellular assays and for binding to the isolated ETV6 PNT domain as monitored by nuclear magnetic resonance (NMR) spectroscopy. Although no inhibitory compounds were successfully identified, the development, validation and implementation of these assays will be discussed herein.

\section{Materials and Methods}

\section{Chemicals for Screening}

Screening compounds for the cellular assays consisted of 16,000 compounds from the Maybridge Hitfinder collection, 10,000 compounds from the ChemBridge DIVERset collection, 1,120 compounds from Prestwick Chemicals, 1,280 compounds from the Sigma LOPAC library, 2,000 compounds from the Microsource Spectrum collection, 2,697 compounds from the Selleck L1700 Bioactive Compound library, and 500 compounds from Biomol. The compounds were stored in 96 -well plates at $-25^{\circ} \mathrm{C}$ as $5 \mathrm{mM}$ stock solutions in DMSO. In addition, a small molecule library targeting PPIs consisting of 1,534 compounds was provided by the Perturbation of ProteinProtein Interactions (PoPPI) collaborative program (UK). Candidate compounds from the BUDE screening assay were purchased from MolPort for testing in both cellular assays and by NMR spectroscopy.

Vectors and Cloning for the Split Luciferase Protein-fragment Complementation Assay 
The split luciferase protein-fragment complementation assay (PCA) was based on the protocol of Michnick and co-workers. ${ }^{23}$ Sequences encoding ETV6 ${ }^{43-125}$ (residues 43-125 of human ETV6, encompassing the PNT domain; Genbank Gene ID: 2120) with either an A93D or V112E substitution were cloned into either the modified mammalian expression vector pcDNA3.1/Zeo(+) or pcDNA3.1/Neo(+) at the 5 '-end of sequences for humanized Gaussian Luciferase (hGLuc) fragments (Supplemental Table S1). The resulting constructs encoded either A93D- or V112E-PNT domain, a (GGGGS) 2 flexible linker and either hGLuc(1) ${ }^{1-93}$ or hGLuc(2) ${ }^{94-}$ 196. The latter are described herein as N-Luc or C-Luc, respectively. A control set of plasmids containing leucine zippers as the dimerization domains were also provided by Dr. Michnick. ${ }^{23}$

\section{Mammalian Cell Culture}

Human embryonic kidney cells 293 (HEK293) cells were cultured in Dulbecco’s Modified Eagle Medium (DMEM; Gibco) supplemented with 10\% fetal bovine serum (FBS; Sigma) and 1\% antibiotic-antimycotic (Gibco). Unless otherwise noted, this medium was used in all experiments. Stably expressing transformants were treated additionally with either or both 400 $\mu \mathrm{g} / \mathrm{mL} \mathrm{G} 418$ (Gibco) and $50 \mu \mathrm{g} / \mathrm{mL}$ zeocin (Invitrogen). Cells were incubated at $37{ }^{\circ} \mathrm{C}$ with $5 \%$ $\mathrm{CO}_{2}$, and passaged upon reaching approximately $75-85 \%$ confluency.

\section{Transient Expression for Validation of the PCA}

HEK293 cells were seeded in 96-well clear bottom black microplates (Corning \#6005182) at 15,000 cells/well and incubated at $37^{\circ} \mathrm{C}$. After $24 \mathrm{~h}$, the medium was aspirated and $100 \mu \mathrm{L}$ of fresh medium added. For transfection of a single species of DNA, $20 \mathrm{ng} / \mu \mathrm{L}$ of plasmid was added to OPTIMEM (Gibco), and for transfection of two species of DNA, $10 \mathrm{ng} / \mu \mathrm{L}$ of each plasmid was 
added to OPTIMEM. Lipofectamine 2000 (Invitrogen) was diluted to 8\% in OPTIMEM and added to the DNA at a 1:1 v:v ratio and incubated for $5 \mathrm{~min}$ at room temperature. After incubation, 10 $\mu \mathrm{L}$ of the total prepared DNA, OPTIMEM and Lipofectamine 2000 were added to each well. Cells were incubated at $37^{\circ} \mathrm{C}$ for either 24,48 or $72 \mathrm{~h}$. Prior to the luminescence reading, $50 \mu \mathrm{L}$ of cell medium was removed and an equal volume of NanoFuel GLOW Assay (Nanolight Technology) for Gaussia luciferase was then added to each well. After incubation in the dark at ambient temperature for $5 \mathrm{~min}$, the luminescence output was read for one second with a Varioskan LUX multimode microplate reader.

\section{Establishment of a Stably Expressing PNT Domain PCA System}

HEK293 cells were seeded in 6-well microplates at 400,000 cells/well and grown overnight to approximately $80 \%$ confluence. Cell medium was changed and the cells were transfected with Lipofectamine 2000 utilizing $25 \mathrm{ng} / \mu \mathrm{L}$ DNA for single plasmid transfections or $12.5 \mathrm{ng} / \mu \mathrm{L}$ DNA for each plasmid in a double plasmid transfection. After $24 \mathrm{~h}$, the medium was aspirated, fresh medium was added and the cells were incubated again overnight. After $48 \mathrm{~h}$, selection was introduced by incubating cells with medium supplemented with the corresponding antibiotic(s), replacing medium every 2-3 days, and splitting cells when $80 \%$ confluency was achieved. The resulting stable transformants were stored in liquid nitrogen.

\section{High-throughput PCA Screening}

For screening, stable transformants of A93D-PNT/N-Luc(Neo) and V112E-PNT/CLuc(Zeo) were plated at 40,000 cells/well in 96-well clear bottom black microplates (Corning \#6005182) and incubated overnight at $37^{\circ} \mathrm{C}$. Compound plates were thawed and compounds were 
added to cells using a BioRobotics BioGrid Robot Microarrayer Model equipped with a 96-pin tool with either $0.7 \mathrm{~mm}$ or $0.4 \mathrm{~mm}$ diameter pins. After a $4 \mathrm{~h}$ incubation at $37^{\circ} \mathrm{C}$, a $1: 1$ ratio of NanoFuel GLOW Assay reagent was added to the cells and plates were incubated in the dark at ambient room temperature for 15 min. Luminescence output was then read with a Varioskan LUX multimode or BioTek Neo 2 microplate reader.

\section{Secondary PCA}

Compounds that yielded a lower luminescence in the initial PCA screens were re-tested at different concentrations against cells stably expressing the split luciferases fused to ETV6 PNT domains or leucine zippers. The latter served as a specificity control. Cells were seeded at 40,000 cells per well in 96-well plates and incubated at $37^{\circ} \mathrm{C}$ overnight. The selected compounds were added to wells in duplicate at final concentrations of $1,3,10$ and $30 \mu \mathrm{M}$. After $4 \mathrm{~h}$ incubation, cells were visually examined to determine if the compound caused toxicity or precipitated from solution. Luminescence was read as previously described.

\section{Yeast Two-hybrid Assay Development}

The two-hybrid assay consists of bait and prey plasmids and a yeast reporter strain. The bait plasmids expressed, from a constitutive $A D H 1$ promoter, the Oct1 POU DNA-binding domain alone (pIS341) or a fusion between the Oct1 POU DNA-binding domain and the A93D-PNT domain (pIS586). They are ARS-CEN (single copy) plasmids with a TRP1 marker. The prey plasmids expressed the NLS-B42 activation domain (AD) alone (pIS580) or a fusion between the $\mathrm{AD}$ and V112E-PNT domain (pIS591). These genes are under control of an inducible GAL1 promoter on 2 micron (multicopy) plasmids with a LEU2 marker. 
Saccharomyces cerevisiae strain ISY361 was constructed from strain W303. It contains two integrated reporter genes. The HIS3 reporter with a minimal core promoter was integrated at an ade 8 disruption with plasmid pIS452. ${ }^{27}$ The lacZ reporter was integrated at a lys 2 disruption with pIS341. ${ }^{27}$ The expression of the two reporter genes is controlled by 4 upstream POU binding sites. The genotype is MAT $\alpha$, ade2-1, his3-11,15, leu2-3,112, trp1-1, ura3-1, can1-100, lys2::POU ops-LACZ, ade8::POU ops-HIS3.

ISY361 was transformed with bait plasmid pIS586 and prey plasmid pIS591 to generate the strain ISY361+/+ expressing POU-A93D bait and AD-V112E prey. A strain containing bait plasmid pIS586 and prey plasmid pIS580 lacking the V112E domain was also generated to serve as a control and is referred to as ISY361+/-.

\section{High-throughput Yeast Two-hybrid Screening}

Yeast media were prepared with reagents obtained from Becton Dickinson and Sunrise Science Products. Strains were grown overnight at $30{ }^{\circ} \mathrm{C}$ with agitation in Synthetic Complete (SC) medium lacking Leu and Trp and containing 2\% glucose. Cells were harvested by centrifugation at 4,700 $\mathrm{g}$ for $5 \mathrm{~min}$, pellets were rinsed twice with sterile distilled water and cells were suspended at $\mathrm{OD}_{595} 0.01$ in SC medium lacking Leu, Trp and His and containing 2\% galactose instead of glucose. The suspension also contained $2 \mathrm{mM}$ 3-amino-1,2,4-triazole, which is used to minimize the effect of basal expression of HIS3. ${ }^{28,29}$ Cell suspension $(100 \mu \mathrm{L})$ was distributed to wells of sterile clear flat bottom polystyrene 96-well microplates (Costar \# 3370) using a dispensing 8-channel pipettor. Eight wells were reserved for blanks. Chemicals were added to each well using a Biorobotics Biogrid II robot equipped with either a $0.7 \mathrm{~mm}$ or $0.4 \mathrm{~mm}$ diameter 96-pin tool. The yeast plates were incubated at $30^{\circ} \mathrm{C}$ in a humidified chamber without agitation 
for $48 \mathrm{~h}$. The cells were suspended by gently vortexing for 1 min and $\mathrm{OD}_{595}$ readings were obtained using an Opsys MR 96-well plate reader (Dynex Technologies). OD 595 readings of wells containing only medium were defined as $0 \%$ growth and $\mathrm{OD}_{595}$ readings of wells containing yeast but no screening chemicals were defined as $100 \%$ growth.

The compounds were tested at either a final concentration of 10 or $15 \mu \mathrm{M}$. Compounds showing growth inhibition were typically re-tested at two different concentrations in duplicate in medium lacking His and in medium containing $20 \mu \mathrm{g} / \mathrm{mL}$ L-His. Compounds showing more growth inhibition in medium lacking His than in medium containing His were re-tested in two or more replicates over a concentration range.

\section{BUDE Virtual Screening}

Virtual ligand screening was carried out on the University of Bristol's high performance computing system BlueCrystal with the docking program BUDE (Version 1.2.9) ${ }^{25}$ utilizing the University of California San Francisco ZINC8 virtual ligand database. ${ }^{30}$ Coordinates of monomer subunits were taken from the X-ray crystallographic structure of the polymeric ETV6T PNT domain (PDB: 1LKY) and used as representative of the wild-type interfaces in the A93D-PNT or V112R-PNT domain backgrounds. In brief, the protein structure, known as the receptor, was placed as a mol2 file with the origin at the wild-type A93 or V112 residue for the V112R- or A93D-PNT domain, respectively. Centered on the origin, the docking grid search volume was a $15 \AA \times 15 \AA$ x $15 \AA$ cube. Members of the ZINC8 library, consisting of greater than 8 million ligands (each having approximately 20 conformers per ligand generated), were tested for docking around the origin. 
A second BUDE screen with residues of the intermolecular K99-D101 salt bridge set as the origins. In addition, an ensemble of 10 different structures, obtained from 10 ns steps of a 100 ns molecular dynamic (MD) simulation performed with GROMACS, ${ }^{31}$ were used as the receptors. Docking was carried out using the top 200,000 compounds, and their conformers, that exhibited the lowest binding energies in the first BUDE screen, described above.

\section{Molecular Dynamics Simulations on Docked Candidates}

Ligands that were targeted for the interfacial residues of the ETV6 PNT domain were ranked on their predicted free energy of binding. The top 500 compounds to each interface underwent a short $10 \mathrm{~ns}$ MD simulation of the ligand-protein complex to determine if they maintained a stable interaction. In brief the MD simulations were performed with AMBER (Version 16) ${ }^{32}$ using the FF14SB-ildn forcefield, TIP3P water and ligand parameters taken from the GAFF (General Amber Force Field). ${ }^{33}$ The full 10 ns simulations were run with 2 fs integration step size while maintaining a temperature of $300 \mathrm{~K}$ and pressure of 1 bar. Resulting ligand rootmean-squared deviation (RMSD) time courses were calculated for the trajectories relative to the initial, midpoint and final poses using CPPTRAJ. ${ }^{34}$ In addition, the trajectories were visualized using VMD (Version 1.9.2) software. ${ }^{35}$

\section{BUDE Candidate Selection and Testing}

Compounds identified by virtual docking underwent several iterations of selection. First, the top ranked poses with the lowest calculated binding energies were manually inspected in Chimera (Version 1.13.1). ${ }^{36}$ For the ligands targeted to the interface, those that had duplicate conformers with low RMSDs during 10 ns MD simulations were preferentially selected over those 
with high RMSDs or that dissociated. The generated list of potential compounds was further refined by considering their commercial availability and selected to give a range of chemical diversity targeting the EH or ML surfaces of the ETV6 PNT domain. In total, 50 compounds were purchased to target the core interfacial residues. Of these, 16 targeted the ML surface around A93 in the V112E-PNT domain structure, 32 targeted the EH surface around V112 in the A93D-PNT domain structure, and 2 targeted both. In addition, 10 compounds were purchased to target the K99-D101 salt bridge (6 targeted D101 and 4 targeted K99).

\section{Testing of Compound Binding by NMR Spectroscopy}

Candidate compounds were tested in vitro for binding to the ${ }^{15} \mathrm{~N}$-labeled PNT domain via ${ }^{15} \mathrm{~N}-\mathrm{HSQC}$ monitored titrations recorded at $25{ }^{\circ} \mathrm{C}$ with Bruker Avance 500 or $600 \mathrm{MHz}$ spectrometers. Isotopically labeled ETV6 $6^{43-125}$ with either an A93D or V112E substitution was expressed in Escherichia coli and purified as described previously. ${ }^{19}$ Purchased compounds were dissolved to $50 \mathrm{mM}$ stock solutions in DMSO. Purified protein samples were at a final concentration of $150 \mu \mathrm{M}$ and volume of $450 \mu \mathrm{L}$ in a standard buffer $(20 \mathrm{mM}$ MOPS, $50 \mathrm{mM} \mathrm{NaCl}$, and $0.5 \mathrm{mM}$ EDTA at $\mathrm{pH} 7.0$ for A93D-PNT domain and $\mathrm{pH} 8.0$ for V112E-PNT domain) with $\mathrm{D}_{2} \mathrm{O}(5 \% \mathrm{v} / \mathrm{v})$ added for signal locking. All compounds were tested at a minimum of 2:1 molar ratio a maximum of 20:1 molar ratio compound to protein. Control titrations with DMSO were also recorded.

\section{Results}

Development of a PCA to Screen for Inhibitors of PNT Domain Association 
Initially, we established and characterized a PCA for monitoring heterodimerization of the A93D- and V112E-PNT domains based on the split Gaussia luciferase methodology. ${ }^{23}$ Various fusion proteins containing the mutant ETV6 PNT domains and either N-Luc or C-Luc fragments were transiently expressed in HEK293 cells (Supplemental Table S2). Cell culture medium alone or cells exposed to the reagents needed for the transient transfections showed luminescence readings of $\sim 20$ on a Varioskan LUX multimode microplate reader. When expressed alone, V112E-PNT/C-Luc, A93D-PNT/C-Luc and A93D-PNT/N-Luc also produced relatively low luminescence readings of $\sim 600$, either 48 or $72 \mathrm{~h}$ post-transfection. Co-expressing A93D- and V112E-PNT domains that can heterodimerize, but fused to the same luciferase fragment, also resulted in a low luminescence reading of $\sim 70$. Introduction of the complementary N-Luc and CLuc luciferase fragments, each linked to the A93D-PNT domain yielded a higher luminescence of 2500. However, this was still low when compared to combinations of A93D-PNT/C-Luc and V112E-PNT/N-Luc or A93D-PNT/N-Luc and V112E-PNT/C-Luc, that showed readings $48 \mathrm{~h}$ post-transfection of 320,000 and 91,000 , respectively. The luminescence readings of these combinations diminished $72 \mathrm{~h}$ post-transfection. The higher luminescence readings of the A93DPNT/C-Luc and V112E-PNT/N-Luc combination compared with the reciprocal combination may indicate that one orientation of the luciferase fragments is more favorable to reconstitution of the active enzyme than the other. Based on these initial studies, the constructs encoding A93D-PNT/CLuc and V112E-PNT/N-Luc were expressed stably in HEK293 cells to facilitate high-throughput screening.

There are no known inhibitors of ETV6 PNT domain polymerization to use as controls. However, the isolated PNT domain has a dominant-negative effect on cells expressing EN, reverting morphology back to wild-type. ${ }^{19}$ Thus, we transiently transfected the A93D-PNT domain 
into the stably expressing HEK293 cells to test for an expected reduction in the luminescence reading due to competition with the A93D-PNT/N-Luc for the V112E-PNT/C-Luc binding interface (Fig. 2A). At $24 \mathrm{~h}$ post-transfection, the A93D-PNT domain caused a significant decrease in luminescence with this cell line, but not with control cells expressing luciferase fragments fused with leucine zippers. At 48 h post-transfection, both systems were affected, but the decrease was most pronounced with the cells for the PNT domain PCA. To a much lesser extent, a transiently transfected empty pcDNA3.1 vector also reduced luminescence for the two systems $48 \mathrm{~h}$ posttransfection. Collectively, these controls define the expected sensitivity to inhibition of PNT domain heterodimerization.

\section{High-throughput Screening using the PNT Domain PCA}

In total, $\sim 18,000$ compounds were screened with the PNT domain PCA assay. Plates were analyzed individually due to the limited stability of the luminescence signal over time and compounds of interest were identified as having a luminescence reading that was more than two standard deviations away from the average luminescence reading of a plate (Fig. 3A). An overall $\sim 1 \%$ hit rate was observed.

Secondary testing of screening hits was performed in the PNT domain PCA and the control leucine zipper PCA systems (Fig. 3B). Compounds were re-tested in duplicates at 1, 3, 10 and 30 $\mu \mathrm{M}$, and cells were examined under the microscope for any toxic effects or evidence of compound precipitation. Out of 179 compounds retested, 83 did not decrease the luminescence in a concentration-dependent manner and were likely artifacts of the initial screens. All 96 of the remaining compounds that showed a concentration-dependent decrease of luminescence in the 
PNT domain PCA exhibited the same pattern with the leucine zipper PCA. Thus, changes in luminescence were likely due to factors other than inhibition of the PNT domain association.

In addition to the secondary cellular screening, 13 of the 96 compounds were purchased and tested for binding in vitro to the PNT domain using NMR spectroscopy. The ${ }^{15} \mathrm{~N}-\mathrm{HSQC}$ spectra of ${ }^{15} \mathrm{~N}$-labelled A93D-ETV6 ${ }^{43-125}$ was recorded upon progressive titration with each compound. Amide ${ }^{1} \mathrm{H}^{\mathrm{N}}$ and ${ }^{15} \mathrm{~N}$ chemical shifts are highly sensitive to even subtle structural changes accompanying ligand binding. ${ }^{37}$ In no case were any chemical shift perturbations observed, indicating no detectable binding (Supplemental Table S3).

\section{Development of a Yeast Two-hybrid Assay to Screen for Inhibitors of PNT Domain Association}

The yeast two-hybrid assay involved several plasmids in auxotrophic yeast strains (Fig. 1B). The bait plasmid pIS586 encoded a fusion between the POU DNA-binding domain and the A93D-PNT domain, the prey pIS591 encoded a fusion between the NLS-B42 activation domain and the V112E-PNT domain, and the prey control pIS580 lacked the PNT domain. To validate the assay, we showed that the yeast strain ISY361+/+ containing the "bait + prey" plasmids indeed grew in the absence of His in the medium, whereas the "bait + control" strain ISY361+/- lacking the V112E-PNT domain showed little to no growth (Fig. 2B). Growth was restored upon addition of His to the latter, indicating that lack of growth was specifically due to lack of HIS3 gene expression.

\section{High-throughput Screening using the Yeast Two-hybrid Assay}

In total, over 8,000 compounds were screened in the yeast two-hybrid assay. The effects of the compounds on yeast cell growth were displayed as histograms for each library, with 
representative examples in Fig. 4A. In general, the libraries showed a narrow growth distribution range, with most compounds affecting growth by less than $10 \%$.

Secondary screening was carried out using multiple concentrations of 242 of the hits from the primary screen. Several compounds, such as tannic acid (Fig. 4B) and acivicin (Fig. 4C), showed a decrease of cell growth in the "bait + prey" strain that could be restored with addition of histidine and exhibited no decreased cell growth in the "bait + control" strain. It was subsequently recognized that acivicin is a glutamine analogue and can inhibit $\gamma$-glutamyltransferase, ${ }^{38}$ which is needed for histidine biosynthesis. While such compounds are false positives of the two-hybrid screen, they do validate that a growth response should be observed if a compound interferes with histidine biosynthesis through inhibition of PNT domain association.

In total, three compounds (paromomycin, tannic acid, sanguinarine) passed the secondary screening and have no reported impact on the biosynthesis of histidine. Thus, they were purchased for final testing utilizing NMR spectroscopy. NMR-monitored titrations were carried out with both ${ }^{15} \mathrm{~N}$-labelled A93D- and V112E-ETV6 $63-125$. In all cases, no amide ${ }^{1} \mathrm{~N}^{\mathrm{H}}{ }^{15} \mathrm{~N}$ chemical shift perturbations we observed, indicating that the three compounds do not detectably bind to the monomeric PNT domains in vitro (Supplemental Table S3). The reasons underlying their effects on the yeast two-hybrid screen are currently unknown.

\section{Virtual Screening for Inhibitors of ETV6 PNT Domain Self-Association}

Virtual screening for ligands predicted to bind the ETV6 PNT domain self-association interfaces was performed using the BUDE algorithm with a high-performance computer cluster. Over 160 million total poses of $\sim 8$ million ligands from the ZINC8 library, averaging 20 conformers per molecule, were tested. Virtual docking of these molecules was initially directed 
towards $15 \AA$ x $15 \AA$ x $15 \AA$ search boxes centered on the A93 and V112 interfacial regions of the PNT domain (Fig. 5).

After running BUDE targeted to each PNT domain hydrophobic interface, the top 500 compounds predicted to have the best binding energies were selected for short MD simulations. The simulations were carried out to determine if the compounds would theoretically remain associated with the PNT domain over a 10 ns sampling. The coordinate RMSDs of each ligand throughout the simulation versus its initial, midpoint ( $5 \mathrm{~ns})$ and endpoint (10 ns) pose were plotted. Based on these RMSD plots, ligands were scored as "excellent", "good", "mediocre" and "bad" (Fig. 6). In parallel, every compound in the top 500 was visually analyzed for common structural motifs and suitable interactions.

Compounds selected for testing by NMR spectroscopy and the screening assays had excellent or good scores in MD simulations, appeared to interact closely with the PNT domain, were commercially available and represented a range of chemical motifs to increase diversity. Preference was given to compounds that were predicted to bind in multiple conformers. Several additional compounds that had a BUDE ranking $>500$ were also selected due to possessing certain structural motifs, such as carboxylates or protonated amines, that could potentially interact with complementary motifs of the PNT domain. Collectively, this resulted in 35 and 17 compounds predicted to bind the hydrophobic interfaces centered around A93 (ML surface) and V112 (EH surface) of the V112E- or A93D-PNT domain monomers, respectively (Supplemental Fig. S1).

A second screening was subsequently carried out to target the interfaces around K99 and D101. These residues form an intermolecular salt bridge (Fig. 5). Furthermore, to help account for protein dynamics, an ensemble of protein structures taken at $10 \mathrm{~ns}$ steps of $100 \mathrm{~ns}$ MD simulations were used for docking. To accelerate the process, we also focused on only the top 200,000 
compounds from the first BUDE screen and their respective conformers. In total, $\sim 4$ million poses of ligands were tested for docking to the 10 different A93D- or V112E-PNT domain structures. The resulting top 500 candidates were visually inspected and 10 compounds with chemical diversity were selected for testing (Supplemental Fig. S3).

\section{Experimental Testing of the Virtual Screening}

A total of 60 candidate compounds from two BUDE screens were purchased for further testing. All compounds were used for NMR-monitored titrations with samples of ${ }^{15} \mathrm{~N}$-labelled A93D- or V112E-ETV6 ${ }^{43-125}$, as appropriate. None were found to bind with any detectable affinity as evidenced by the lack of amide ${ }^{1} \mathrm{~N}^{\mathrm{H}}{ }^{15} \mathrm{~N}$ chemical shift perturbations (Fig. 7A and Supplemental Table S3). In parallel, the compounds were screened in both the yeast two-hybrid and the mammalian cell assays. No compounds were growth inhibitory in the yeast assay, and in the PNT domain PCA, one compound was identified as a screening hit (Fig. 7B). However, this compound also demonstrated reduced luminescence in the leucine zipper PCA, possibly inhibiting luciferase or other confounding factors related to cellular proliferation. Despite extensive efforts, virtual screening did not lead to the identification of any compounds that bind in vitro to the ETV6 PNT domain.

\section{Discussion}

In this study, we established three complementary approaches to screen for potential inhibitors of ETV6 PNT domain polymerization. Unfortunately, we did not succeed in discovering any small molecules that bound the PNT domain in vitro or disrupted its self-association in vivo. 
Nevertheless, valuable insights were gained that should facilitate future studies aimed at modulating protein-protein interactions with systems similar to ETV6.

The mammalian and yeast cell assays were designed for unbiased high-throughput screening of compounds in a cellular context, with a readout that is dependent upon disruption of a heterodimer model of the ETV6 polymer. However, in the PCA assay, screening hits can arise not only from inhibition of heterodimerization, but also from perturbation of split luciferase reconstitution or luciferase activity, as well as due to cytotoxicity or inhibition of cellular proliferation. Therefore, the leucine zipper PCA was critical as a control assay to determine whether any reduction in luminescence was due to the latter confounding effects. Similarly, in the yeast screening assay, the use of a control vector and addition of histidine to secondary testing of screening hits for growth rescue were used to eliminate any compounds that caused cell death or inhibition of the histidine biosynthetic pathway.

It is worth emphasizing that the ETV6 A93D- and V112E-PNT domains heterodimerize with low nM affinity. ${ }^{18,19}$ This certainly presents a challenge in discovering potentially rare compounds in chemical libraries with comparable affinities to effectively disrupt this tight proteinprotein interaction. A mitigating strategy might involve the initial use of PNT domain variants with additional mutations to weaken their association and thereby reduce the stringency of the assay. Such variants may be inspired by detailed biophysical analyses of the ETV6 PNT domain interfaces. ${ }^{39}$ In addition, it would be beneficial to use cell-based "up" assays that positively select for disruption of PNT domain association or employ a readout that increases, rather than decreases, with this result.

To this end, we explored use of a yeast two-hybrid assay where expression of HIS3 and $L a c Z$ reporter genes are dependent upon PNT domain heterodimerization. However, this assay as 
implemented was not useful for discovery of inhibitors because potential hits in small molecule screens would prevent growth on medium lacking His, and loss of LacZ expression, which could also be produced by various alternative effects unrelated to inhibition of the PNT domain interaction. Ideally, the screening assay could be modified to include a reporter such as $C A N 1$ or $U R A 3$, where inhibitors of the interaction would prevent activation, allowing detection by growth on canavanine or 5-fluoroorotic acid, respectively. ${ }^{40}$ Alternatively, yeast-based strategies could also be used such as the repressed transactivator system, where interaction of bait and prey fusions cause repression of gene expression, and inhibitors of the interaction cause gene activation, which is detected by growth of yeast on selective media. ${ }^{41}$ However, this system is currently limited to use with Gal4 DNA-binding domain fusions, and we were unable to detect interaction of PNT fusions in yeast using the Gal4 DNA-binding domain linked to the PNT domain.

In parallel to cellular assays, we undertook a targeted virtual screening approach to search for compounds that bind the known polymerization interfaces of the ETV6 PNT domain. Although BUDE has been successful in identifying inhibitors of PPIs, ${ }^{26}$ and numerous potential ligands were predicted to bind the ETV6 PNT domain in silico, none were found to do so when tested in vitro with NMR spectroscopy or in vivo with cellular assays. However, common motifs that were enriched may serve as starting structures for rational design or further high-throughput screening experiments.

We recognize that this target is particularly challenging since the ETV6 PNT domain polymerizes with high affinity through two relatively large flat interfaces. These comprise complementary central hydrophobic patches ringed by hydrophilic and charged residues with relatively flexible sidechains. Tightly bound ligands typically occupy depressions or cavities on the protein surface, but these features are absent with the PNT domain. However, in the case of 
targeting the intermolecular salt-bridge, the virtual ligands seemed to be predicted to preferentially bind to certain PNT domain structures taken from short MD simulations. This flexibility of the protein may expose conformations better suited for small molecule interactions.

It is unfortunate that some of the best hits from the virtual screen were not commercially available. Experimental testing of these compounds, as well as more in silico hits, might yield success. Indeed, a "similarity paradox" has been described where minor chemical modifications of otherwise similar molecules can render them active or inactive. ${ }^{42}$ This paradox may suggest that, in our efforts to test a diverse set of compounds that sampled chemical space, we missed a high-ranking compound with affinity for the ETV6 PNT domain. Such a large-scale screening approach may be effective, as many protein-protein interaction inhibitors are found through traditional cellular screening only after screening in excess of hundreds of thousands of compounds and carrying out structure-activity relationship studies to optimize initially detected weak-binding leads. $^{43}$

Fragment-based drug design and disulfide tethering, combined with combinatorial chemistry, are two approaches that could also be undertaken as the next steps in developing an inhibitor against PNT domain polymerization. ${ }^{44-46}$ Inspiration can also be found in the design of cyclic peptides and helix peptide mimetics that weakly bind the SAM domains of the Ship2 and EphA2 receptors. ${ }^{47,48}$ In all cases, virtual screening could be used to narrow down potential chemical motifs of interest for a more targeted screening approach. Collectively, such a multipronged strategy may lead to the discovery of a potentially new class of therapeutics that prevent the polymerization of chimeric oncoproteins resulting from a wide array of ETV6 chromosomal translocations. 


\section{Acknowledgements}

We thank Mark Okon for assistance with NMR spectroscopy, Stephen Michnick for providing starting plasmids for the split luciferase PCA, Andrew Wilson for the PoPPI library, and Poul Sorensen for advice on ETV6 translocations.

Supplemental material is available online with this article.

\section{Declaration of Conflicting Interests}

The authors declared no potential conflicts of interest with respect to the research, authorship, and/or publication of this article.

\section{Funding}

The authors disclosed receipt of the following financial support for the research, authorship, and/or publication of this article: This study was supported by funds from the Canadian Cancer Society Research Institute to I.J.S., L.P.M and M.R., and from the Canadian Institutes of Health Research (CIHR) to L.P.M. C.A.N.G. held graduate scholarships from CIHR and the University of British Columbia. We thank the Advanced Computing Research Centre at Bristol University for the provision of high performance computing. 


\section{References}

(1) Lopez, R. G.; Carron, C.; Oury, C.; Gardellin, P.; Bernard, O.; Ghysdael, J. TEL Is a Sequence-Specific Transcriptional Repressor. J. Biol. Chem. 1999, 274 (42), 3013230138. https://doi.org/10.1074/jbc.274.42.30132.

(2) Hock, H.; Meade, E.; Medeiros, S.; Schindler, J. W.; Valk, P. J. M.; Fujiwara, Y.; Orkin,

S. H. Tel / Etv6 Is an Essential and Selective Regulator of Adult Hematopoietic Stem Cell Survival Tel / Etv6 Is an Essential and Selective Regulator of Adult Hematopoietic Stem Cell Survival. Genes Dev 2004, 18 (19), 2336-2341. https://doi.org/10.1101/gad.1239604.

(3) Wang, L. C.; Kuo, F.; Fujiwara, Y.; Gilliland, D. G.; Golub, T. R.; Orkin, S. H. Yolk Sac Angiogenic Defect and Intra-Embryonic Apoptosis in Mice Lacking the Ets-Related Factor TEL. EMBO J. 1997, 16 (14), 4374-4383.

https://doi.org/10.1093/emboj/16.14.4374.

(4) Odero, M. D.; Carlson, K.; Calasanz, M. J.; Lahortiga, I.; Chinwalla, V.; Rowley, J. D. Identification of New Translocations Involving ETV6 in Hematologic Malignancies by Fluorescence in Situ Hybridization and Spectral Karyotyping. Genes Chromosom. Cancer 2001, 31 (2), 134-142. https://doi.org/10.1002/gcc.1127.

(5) Letessier, A.; Ginestier, C.; Charafe-Jauffret, E.; Cervera, N.; Adélaïde, J.; Gelsi-Boyer, V.; Ahomadegbe, J. C.; Benard, J.; Jacquemier, J.; Birnbaum, D.; Chaffanet, M. ETV6 Gene Rearrangements in Invasive Breast Carcinoma. Genes Chromosom. Cancer 2005, 44 (1), 103-108. https://doi.org/10.1002/gcc.20200.

(6) Knezevich, S. R.; McFadden, D. E.; Tao, W.; Lim, J. F.; Sorensen, P. H. B. A Novel ETV6-NTRK3 Gene Fusion in Congenital Fibrosarcoma. Nat. Genet. 1998, 18, 184-187. https://doi.org/10.1016/S0022-3468(87)80123-9. 
(7) Golub, T. R.; Goga, A.; Barker, G. F.; Afar, D. E.; McLaughlin, J.; Bohlander, S. K.;

Rowley, J. D.; Witte, O. N.; Gilliland, D. G. Oligomerization of the ABL Tyrosine Kinase by the Ets Protein TEL in Human Leukemia. Mol. Cell. Biol. 1996, 16 (8), 4107-4116.

(8) Golub, T. R.; Barker, G. F.; Lovett, M.; Gilliland, D. G. Fusion of PDGF Receptor $\beta$ to a

Novel Ets-like Gene, Tel, in Chronic Myelomonocytic Leukemia with t(5;12)

Chromosomal Translocation. Cell 1994, 77 (2), 307-316. https://doi.org/10.1016/00928674(94)90322-0.

(9) Lacronique, V.; Boureux, A.; Della Valle, V.; Poirel, H.; Tran Quang, C.; Mauchauffé, M.; Berthou, C.; Lessard, M.; Berger, R.; Ghysdael, J.; Bernard, O. A. A TEL-JAK2 Fusion Protein with Constitutive Kinase Activity in Human Leukemia. Science (80-. ). 1997, 278 (5341), 1309-1312. https://doi.org/10.1126/science.278.5341.1309.

(10) Baens, M.; Peeters, P.; Guo, C.; Aerssens, J.; Marynen, P. Genomic Organization of the TEL: The Human ETS-Variant Gene 6. Genome Res. 1996, 6, 404-413. https://doi.org/10.1111/j.1349-7006.1992.tb02745.x.

(11) Bohlander, S. K. ETV6: A Versatile Player in Leukemogenesis. Semin. Cancer Biol. 2005, 15 (3), 162-174. https://doi.org/10.1016/j.semcancer.2005.01.008.

(12) Kim, C. A.; Bowie, J. U. SAM Domains : Uniform Structure, Diversity of Function. Trends Biochem. Sci. 2003, 28 (12), 625-628.

(13) Tognon, C. E.; Mackereth, C. D.; Somasiri, A. M.; McIntosh, L. P.; Sorensen, P. H. B. Mutations in the SAM Domain of the ETV6-NTRK3 Chimeric Tyrosine Kinase Block Polymerization and Transformation Activity. Mol. Cell. Biol. 2004, 24 (11), 4636-4650. https://doi.org/10.1128/MCB.24.11.4636-4650.2004.

(14) Tran, H. H.; Kim, C. A.; Faham, S.; Siddall, M.; Bowie, J. U. Native Interface of the SAM 
Domain Polymer of TEL. 2002, 6, 1-6.

(15) Lannon, C. L.; Sorensen, P. H. B. ETV6-NTRK3: A Chimeric Protein Tyrosine Kinase with Transformation Activity in Multiple Cell Lineages. Semin. Cancer Biol. 2005, 15 (3), 215-223. https://doi.org/10.1016/j.semcancer.2005.01.003.

(16) Tognon, C. E.; Martin, M. J.; Moradian, A.; Trigo, G.; Rotblat, B.; Cheng, S.-W. G.;

Pollard, M.; Uy, E.; Chow, C.; Carboni, J. M.; Gottardis, M. M.; Pollak, M.; Morin, G. B.; Sorensen, P. H. B. A Tripartite Complex Composed of ETV6-NTRK3, IRS1 and IGF1R Is Required for ETV6-NTRK3-Mediated Membrane Localization and Transformation. Oncogene 2012, 31 (10), 1334-1340. https://doi.org/10.1038/onc.2011.323.

(17) Wai, D.; Knezevich, S.; Lucas, T.; Jansen, B.; Kay, R.; Sorensen, P. H. B. The ETV6NTRK3 Gene Fusion Encodes a Chimeric Protein Tyrosine Kinase That Transforms NIH3T3 Cells. Oncogene 2000, 19, 906-915.

(18) Kim, C. A.; Phillips, M. L.; Kim, W.; Gingery, M.; Tran, H. H.; Robinson, M. A.; Faham, S.; Bowie, J. U. Polymerization of the SAM Domain of TEL in Leukemogenesis and Transcriptional Repression. EMBO J. 2001, 20 (15), 4173-4182. https://doi.org/10.1093/emboj/20.15.4173.

(19) Cetinbas, N.; Huang-Hobbs, H.; Tognon, C.; Leprivier, G.; An, J.; McKinney, S.; Bowden, M.; Chow, C.; Gleave, M.; McIntosh, L. P.; Sorensen, P. H. Mutation of the Salt Bridge-Forming Residues in the ETV6-SAM Domain Interface Blocks ETV6-NTRK3Induced Cellular Transformation. J. Biol. Chem. 2013, 288 (39), 27940-27950. https://doi.org/10.1074/jbc.M113.475301.

(20) Hollenhorst, P. C.; McIntosh, L. P.; Graves, B. J. Genomic and Biochemical Insights into the Specificity of ETS Transcription Factors. Annu. Rev. Biochem. 2011, 80, 437-471. 
https://doi.org/10.1146/annurev.biochem.79.081507.103945.

(21) Mackereth, C. D.; Schärpf, M.; Gentile, L. N.; MacIntosh, S. E.; Slupsky, C. M.;

McIntosh, L. P. Diversity in Structure and Function of the Ets Family PNT Domains. $J$.

Mol. Biol. 2004, 342 (4), 1249-1264. https://doi.org/10.1016/j.jmb.2004.07.094.

(22) Potter, M. D.; Buijs, A.; Kreider, B.; van Rompaey, L.; Grosveld, G. C. Identification and Characterization of a New Human ETS-Family Transcription Factor, TEL2, That Is

Expressed in Hematopoietic Tissues and Can Associate with TEL1/ETV6. Blood 2000, 95 (11), 3341-3348. https://doi.org/10.1182/blood.V95.11.3341.

(23) Remy, I.; Michnick, S. W. A Highly Sensitive Protein-Protein Interaction Assay Based on Gaussia Luciferase. Nat. Methods 2006, 3 (12), 977-979. https://doi.org/10.1038/nmeth979.

(24) Herr, W.; Cleary, M. A. The POU Domain: Versatility in Transcriptional Regulation by a Flexible Two-in-One DNA-Binding Domain. Genes Dev. 1995, 9 (14), 1679-1693. https://doi.org/10.1101/gad.9.14.1679.

(25) McIntosh-Smith, S.; Price, J.; Sessions, R. B.; Ibarra, A. A. High Performance in Silico Virtual Drug Screening on Many-Core Processors. Int. J. High Perform. Comput. Appl. 2015, 29 (2), 119-134. https://doi.org/10.1177/1094342014528252.

(26) Smith, S. A.; Sessions, R. B.; Shoemark, D. K.; Williams, C.; Ebrahimighaei, R.; McNeill, M. C.; Crump, M. P.; McKay, T. R.; Harris, G.; Newby, A. C.; Bond, M. Antiproliferative and Antimigratory Effects of a Novel YAP-TEAD Interaction Inhibitor Identified Using in Silico Molecular Docking. J. Med. Chem. 2019, 62 (3), 1291-1305. https://doi.org/10.1021/acs.jmedchem.8b01402.

(27) Sadowski, I.; Su, T.-C.; Parent, J. Disintegrator Vectors for Single-Copy Yeast 
Chromosomal Integration. Yeast 2007, 24 (5), 447-455. https://doi.org/10.1002/yea.1469.

(28) Brennan, M. B.; Struhl, K. Mechanisms of Increasing Expression of a Yeast Gene in Escherichia Coli. J. Mol. Biol. 1980, 136 (3), 333-338. https://doi.org/10.1016/00222836(80)90377-0.

(29) Joung, J. K.; Ramm, E. I.; Pabo, C. O. A Bacterial Two-Hybrid Selection System for Studying Protein-DNA and Protein-Protein Interactions. Proc. Natl. Acad. Sci. U. S. A. 2000, 97 (13), 7382-7387. https://doi.org/10.1073/pnas.110149297.

(30) Sterling, T.; Irwin, J. J. ZINC 15 - Ligand Discovery for Everyone. J. Chem. Inf. Model. 2015, 55 (11), 2324-2337. https://doi.org/10.1021/acs.jcim.5b00559.

(31) Berendsen, H. J. C.; van der Spoel, D.; van Drunen, R. GROMACS: A Message-Passing Parallel Molecular Dynamics Implementation. Comput. Phys. Commun. 1995, 91 (1-3), 43-56. https://doi.org/10.1016/0010-4655(95)00042-E.

(32) Case, D. A.; Cheatham, T. E.; Darden, T.; Gohlke, H.; Luo, R.; Merz, K. M.; Onufriev, A.; Simmerling, C.; Wang, B.; Woods, R. J. The Amber Biomolecular Simulation Programs. J. Comput. Chem. 2005, 26 (16), 1668-1688. https://doi.org/10.1002/jcc.20290.

(33) Wang, J.; Wolf, R. M.; Caldwell, J. W.; Kollman, P. A.; Case, D. A. Development and Testing of a General Amber Force Field. Jounral Comput. Chem. 2004, 25, 1157-1174.

(34) Roe, D. R.; Cheatham, T. E. PTRAJ and CPPTRAJ: Software for Processing and Analysis of Molecular Dynamics Trajectory Data. J. Chem. Theory Comput. 2013, 9 (7), 30843095. https://doi.org/10.1021/ct400341p.

(35) Humphrey, W.; Dalke, A.; Schulten, K. VMD: Visual Molecular Dynamics. J. Mol. Graph. 1996, 14 (1), 33-38. https://doi.org/10.1016/0263-7855(96)00018-5.

(36) Pettersen, E. F.; Goddard, T. D.; Huang, C. C.; Couch, G. S.; Greenblatt, D. M.; Meng, E. 
C.; Ferrin, T. E. UCSF Chimera - A Visualization System for Exploratory Research and Analysis. J. Comput. Chem. 2004, 25 (13), 1605-1612. https://doi.org/10.1002/jcc.20084.

(37) Williamson, M. P. Using Chemical Shift Perturbation to Characterise Ligand Binding.

Prog. Nucl. Magn. Reson. Spectrosc. 2013, 73, 1-16.

https://doi.org/10.1016/j.pnmrs.2013.02.001.

(38) Winkler, M. E.; Ramos-Montanez, S. Biosynthesis of Histidine. EcoSal Plus 2009, 3 (2). https://doi.org/10.1016/j.physbeh.2017.03.040.

(39) Gerak, C. A. N. Insights into the Inhibition of ETV6 PNT Domain Polymerization, 2020.

(40) Vidal, M.; Brachmann, R. K.; Fattaey, A.; Harlow, E.; Boeke, J. D. Reverse Two-Hybrid and One-Hybrid Systems to Detect Dissociation of Protein-Protein and DNA-Protein Interactions. Proc. Natl. Acad. Sci. U. S. A. 1996, 93 (19), 10315-10320. https://doi.org/10.1073/pnas.93.19.10315.

(41) Joshi, P. B.; Hirst, M.; Malcolm, T.; Parent, J.; Mitchell, D.; Lund, K.; Sadowski, I. Identification of Protein Interaction Antagonists Using the Repressed Transactivator TwoHybrid System. Biotechniques 2007, 42 (5), 635-644. https://doi.org/10.2144/000112434.

(42) Bajorath, J. Integration of Virtual and High-Throughput Screening. Nat. Rev. Drug

Discov. 2002, 1 (11), 882-894. https://doi.org/10.1038/nrd941.

(43) Wells, J. A.; McClendon, C. L. Reaching for High-Hanging Fruit in Drug Discovery at Protein-Protein Interfaces. Nature 2007, 450 (7172), 1001-1009. https://doi.org/10.1038/nature06526.

(44) Mayr, L. M.; Bojanic, D. Novel Trends in High-Throughput Screening. Curr. Opin. Pharmacol. 2009, 9 (5), 580-588. https://doi.org/10.1016/j.coph.2009.08.004.

(45) Arkin, M. R.; Tang, Y.; Wells, J. A. Small-Molecule Inhibitors of Protein-Protein 
Interactions: Progressing toward the Reality. Chem. Biol. 2014, 21 (9), 1102-1114.

https://doi.org/10.1016/j.chembiol.2014.09.001.

(46) Scott, D. E.; Bayly, A. R.; Abell, C.; Skidmore, J. Small Molecules, Big Targets: Drug

Discovery Faces the Protein-Protein Interaction Challenge. Nat. Rev. Drug Discov. 2016, 15 (8), 533-550. https://doi.org/10.1038/nrd.2016.29.

(47) Mercurio, F. A.; Di Natale, C.; Pirone, L.; Iannitti, R.; Marasco, D.; Pedone, E. M.;

Palumbo, R.; Leone, M. The Sam-Sam Interaction between Ship2 and the EphA2

Receptor: Design and Analysis of Peptide Inhibitors. Sci. Rep. 2017, 7 (1), 1-11. https://doi.org/10.1038/s41598-017-17684-5.

(48) Mercurio, F. A.; Di Natale, C.; Pirone, L.; Vincenzi, M.; Marasco, D.; De Luca, S.; Pedone, E. M.; Leone, M. Exploring the Ability of Cyclic Peptides to Target SAM Domains: A Computational and Experimental Study. ChemBioChem 2019, 1-11. https://doi.org/10.1002/cbic.201900444. 


\section{Figures}
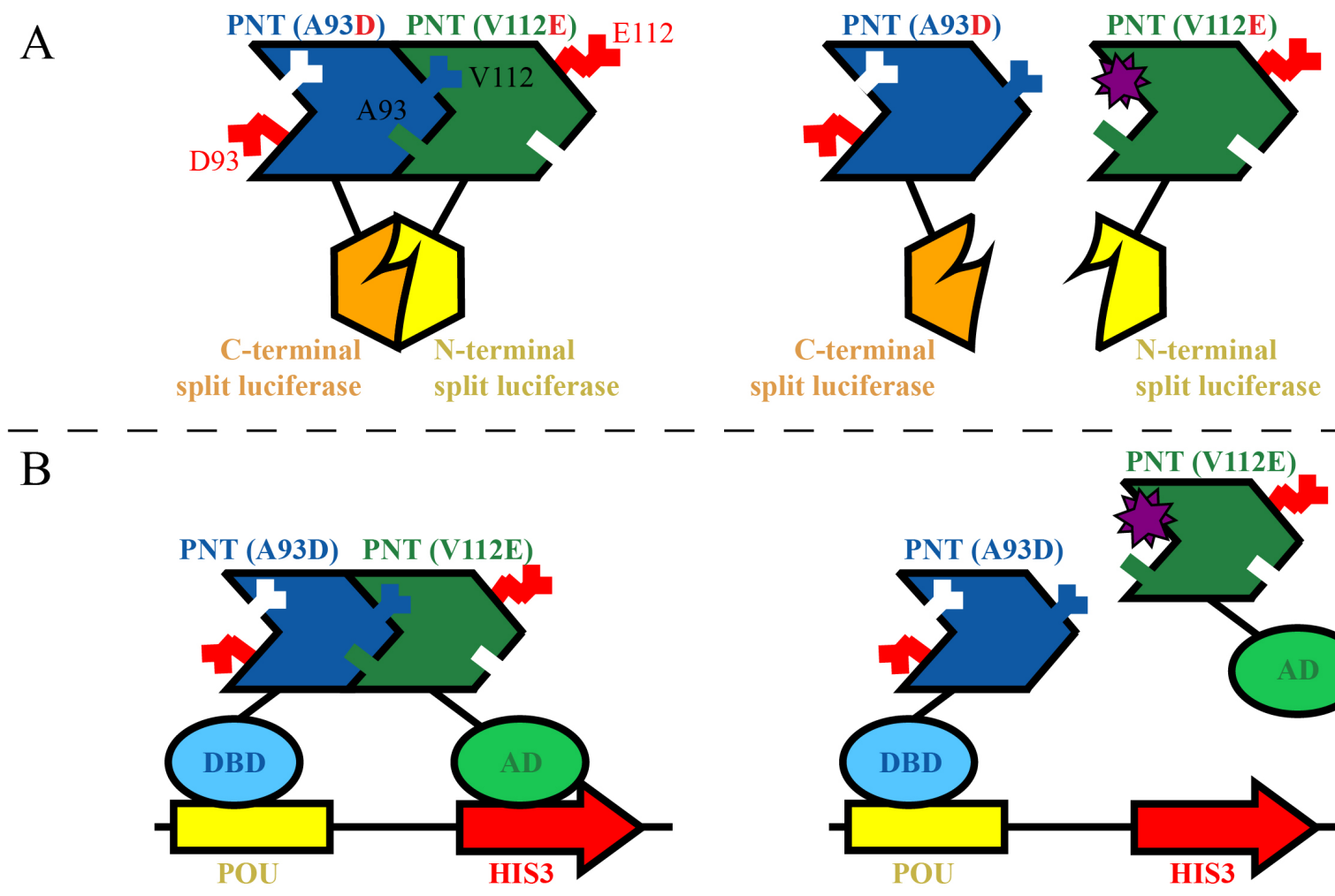

Figure 1. (A) The general principle behind the split-luciferase PCA. When the A93D- and V112EPNT domains heterodimerize (left), the split luciferase fragments assemble into an active enzyme which, upon addition of substrate, generates a luminescence output. If a small molecule (star) disrupts the interaction (right), either by directly binding the interface or by inducing an allosteric conformation change, then the equilibrium shifts away from reconstitution of the luciferase fragments, resulting in reduced luminescence. (B) In the yeast two-hybrid approach, the PNT domains are covalently linked to either a POU DNA-binding domain (DBD) or an activating domain (AD). Heterodimerization induces expression of the HIS3 gene to allow cell growth in medium lacking His (left). If a small molecule disrupts the interaction (right), there is no expression of the HIS3 gene and no yeast growth. Addition of His to the medium enables yeast growth in the absence or presence of an inhibitor of the PNT domain interaction or the histidine 
biosynthetic pathway. These cartoons are highly schematic, especially with respect to the folding of the luciferase fragments.

A

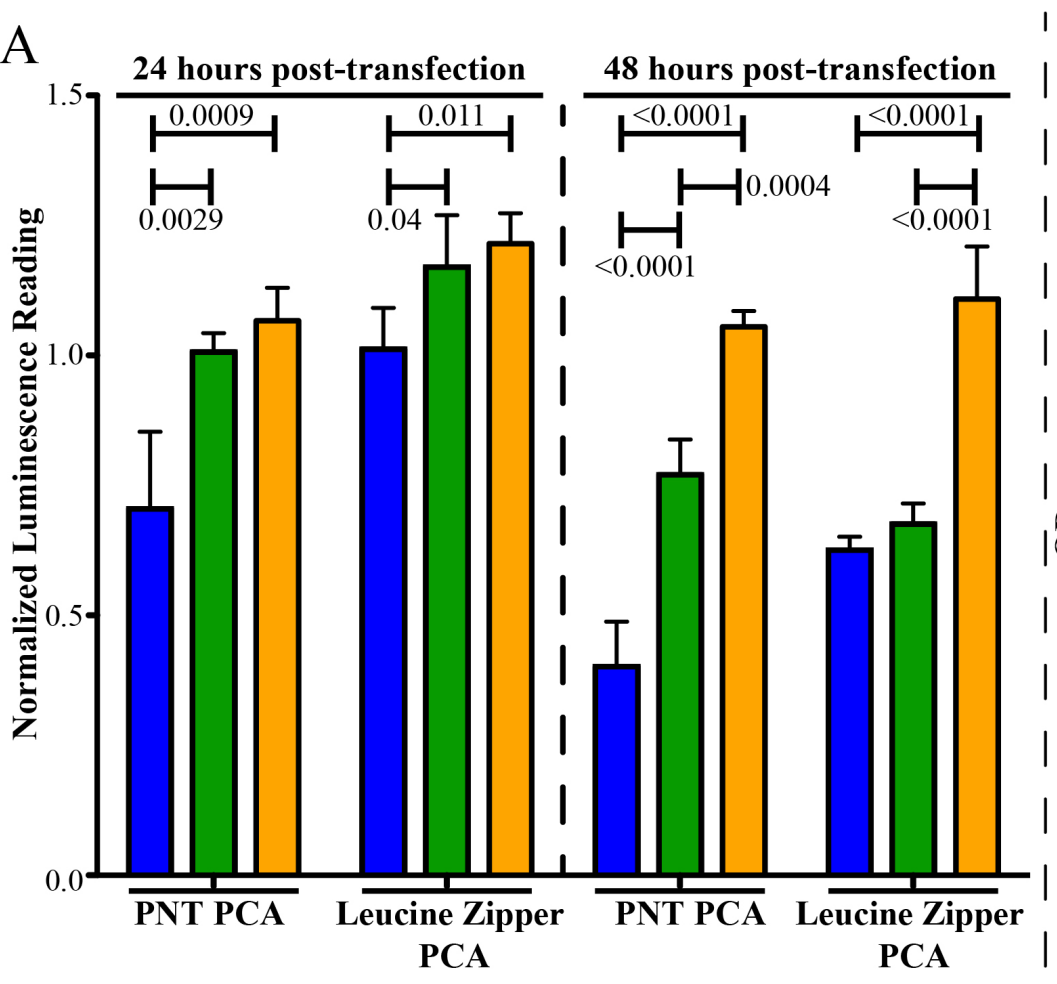

B

A93D PNT domain

pcDNA3.1

Transfection reagents

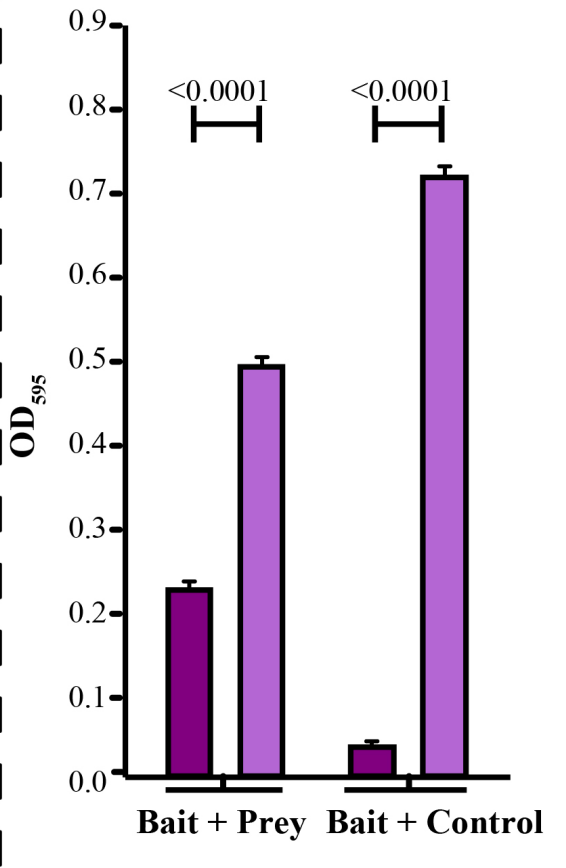

-His

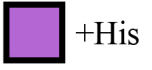

Figure 2. (A) The A93D-PNT domain-expressing and empty pcDNA3.1 vectors were transiently transfected into the PCA systems with luciferase fragments fused to either complementary PNT domains or leucine zippers. Controls with only transfection reagents were also run in parallel. Luminescence readings were normalized to untreated PNT domain or leucine zipper PCAs cells, respectively, with means and standard deviations of the 3 replicates. One-way ANOVA statistical analyses were performed and the calculated $\mathrm{P}$ values are given above the horizontal bars. (B) Yeast growth as detected by OD595. Co-expression of the bait (A93D-PNT Domain/POU DBD) + prey (V112E-PNT domain/AD) plasmids enables ISY361+/+ yeast growth with (light purple) and without (dark purple) addition of His. In contrast, without added His, no growth was seen for 
ISY361+/- yeast containing the bait plasmid and an empty control plasmid that lacks the complementary PNT domain. Each condition was replicated 5 times.

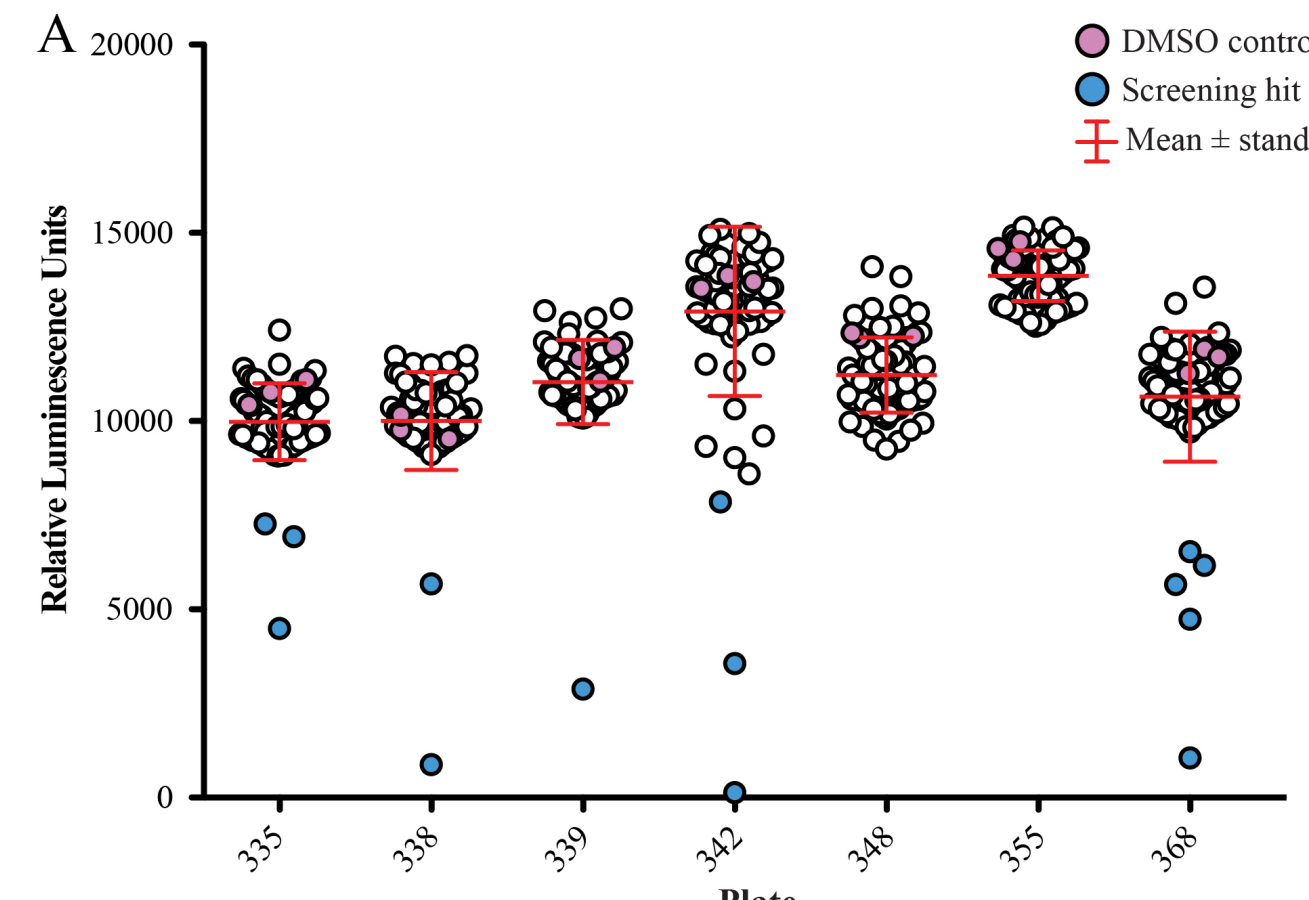

Plate

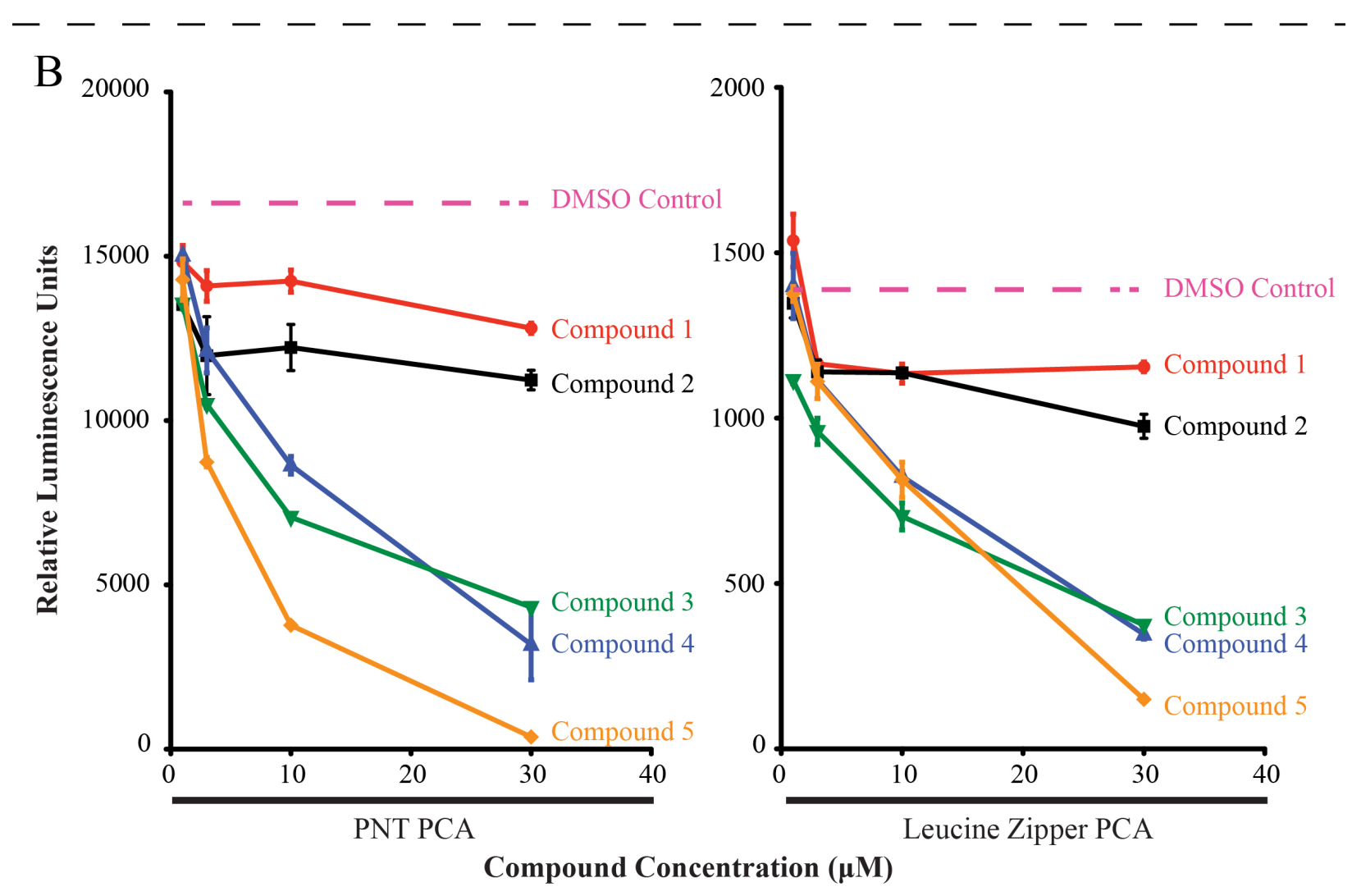


Figure 3. (A) Shown are the results of the PNT domain PCA with compound plates from the Prestwick (335, 338, 339), Biomol (342), Sigma (348, 355) and Microsource (368) libraries. The circles represent the luminescence reading of each well of a 96-well plate. The red bars represent the mean relative luminescence and standard deviation of that plate. Pink circles represent wells that were exposed to only DMSO. An initial screening hit is defined as being more than two standard deviations away from the mean (blue circles) (B) Compounds identified as hits in the initial high-throughput screen were retested for a concentration-dependent response in the PNT domain and leucine zipper PCAs. Compounds were tested in duplicate at 1, 3, 10 and $30 \mu \mathrm{M}$ and cells were visually examined to determine toxicity or compound precipitation. Those that were not cytotoxic and elicited a similar response in the both PCA systems, were likely inhibitors of splitluciferase reconstitution, luciferase activity itself or another variable. Compounds 1-2 represent examples of artifacts of the original, large-scale screen whereas compounds 3-5 represent examples of concentration-dependent responses. Compound 1: $( \pm)$-pindobind; Compound 2: gitoxigenin diacetate; Compound 3: rosolic acid; Compound 4: gambogic acid amide; Compound 5: 3,4-dimethoxydalbergione. 

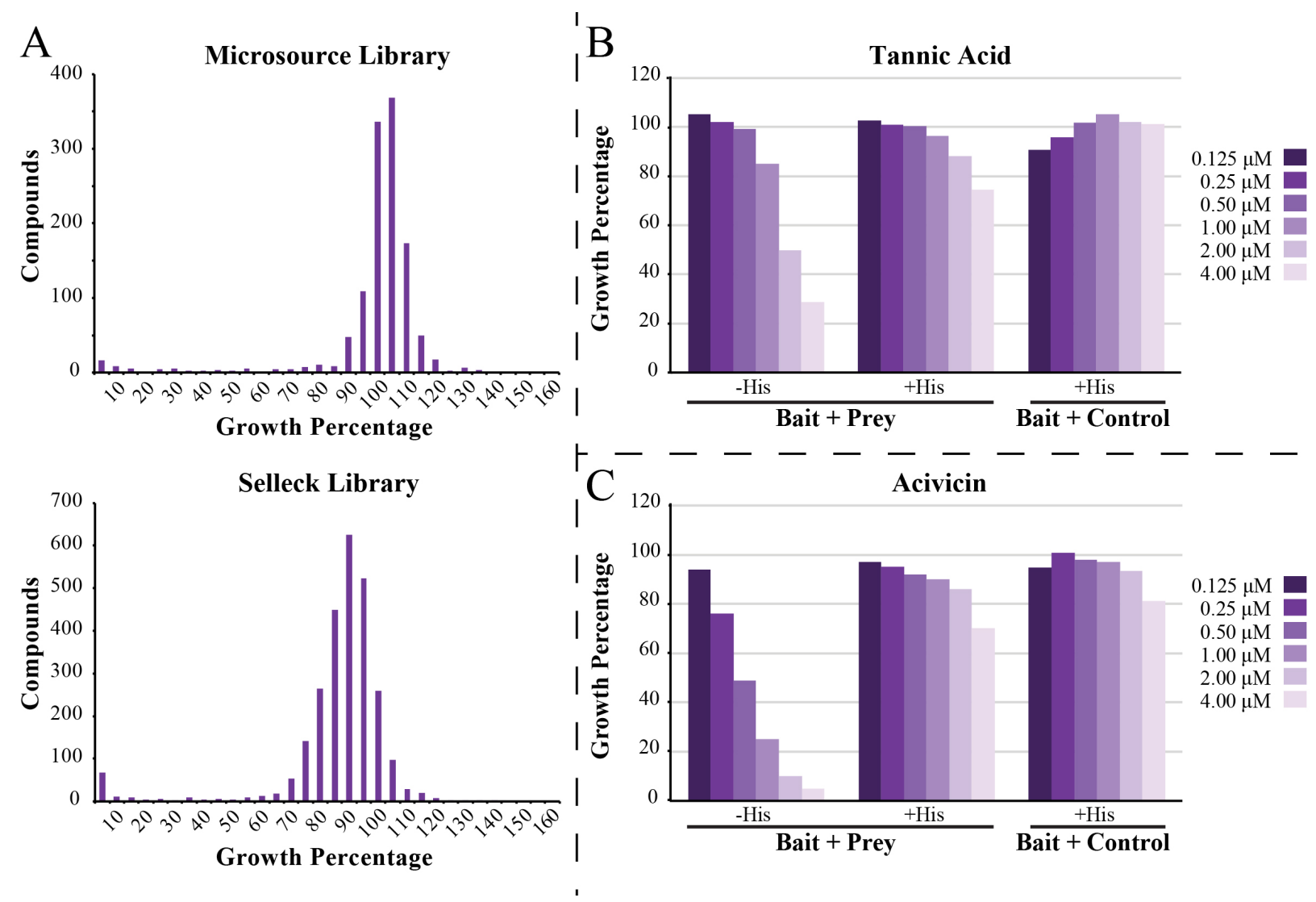

Figure 4. (A) Shown are two compound libraries that were tested in the yeast two-hybrid assay with ISY361+/+ co-expressing bait (A93D-PNT Domain/POU DBD) and prey (V112E-PNT domain/AD) plasmids. The histograms summarize the number of compounds versus growth of untreated cells, defined as $100 \%$. Compounds causing reduced growth were subsequently carried on to secondary testing. Both tannic acid (B) and acivicin (C) showed concentration-dependent inhibition of the growth of yeast containing the "bait + prey" plasmids. This could be rescued through addition of His, indicating that neither compound is toxic to the cells. A similar pattern was seen with ISY361+/- yeast harboring the "bait + control" plasmids, whereby His rescues the cell growth in absence of a functioning HIS3 gene. Acivicin was later found to be an inhibitor of $\gamma$-glutamyltransferase which is necessary for histidine synthesis. 


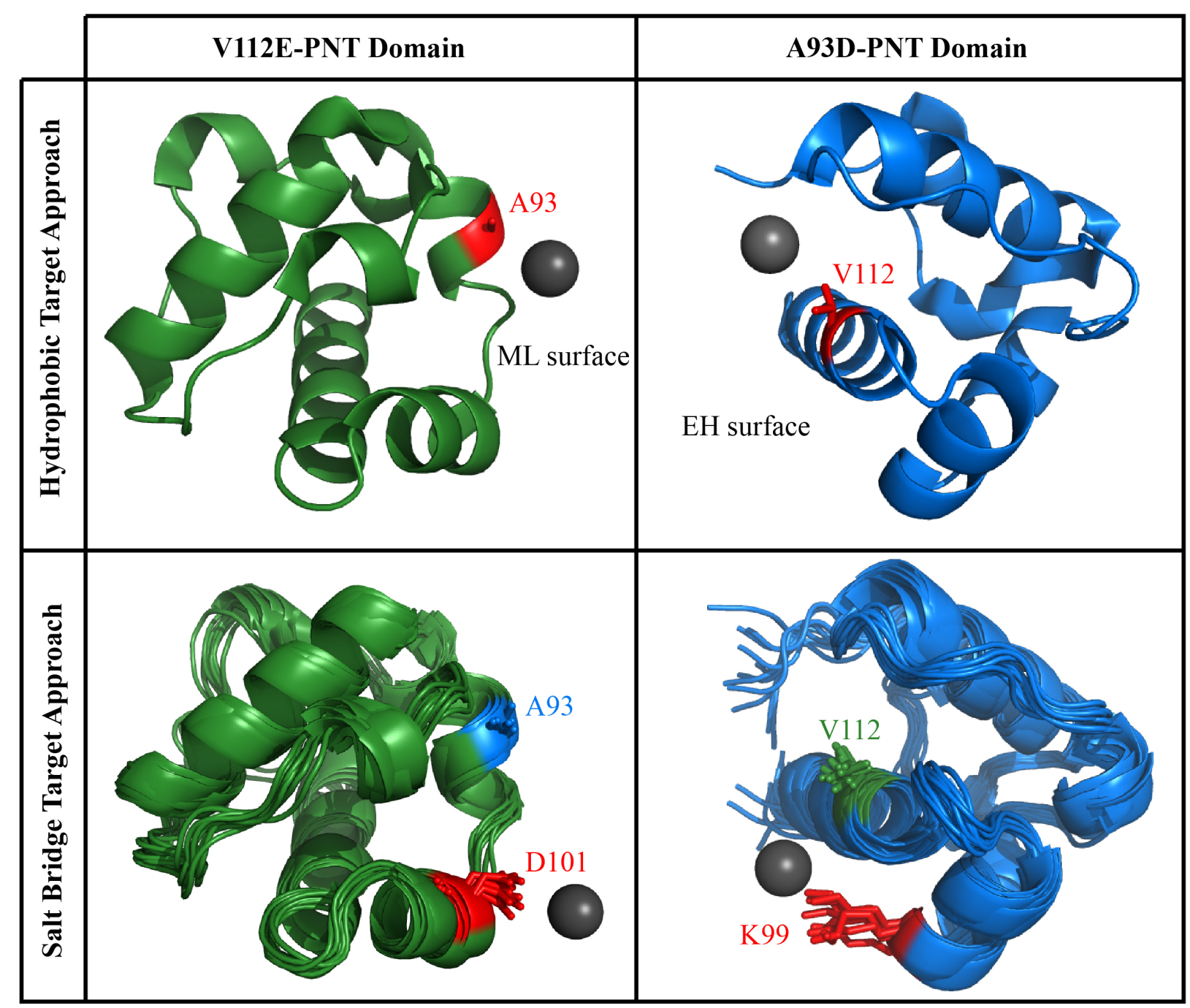

Figure 5. General overview of the BUDE screening. The origin for the starting position of the ligand in the virtual screen is indicated by the grey sphere and the search space was centered around this point. To target the hydrophobic interfaces (upper), PNT domain structures were taken from (PDB: 11KY). To target the flanking salt bridge (lower), 10 structures from a $100 \mathrm{~ns}$ molecular dynamics simulation were chosen. 

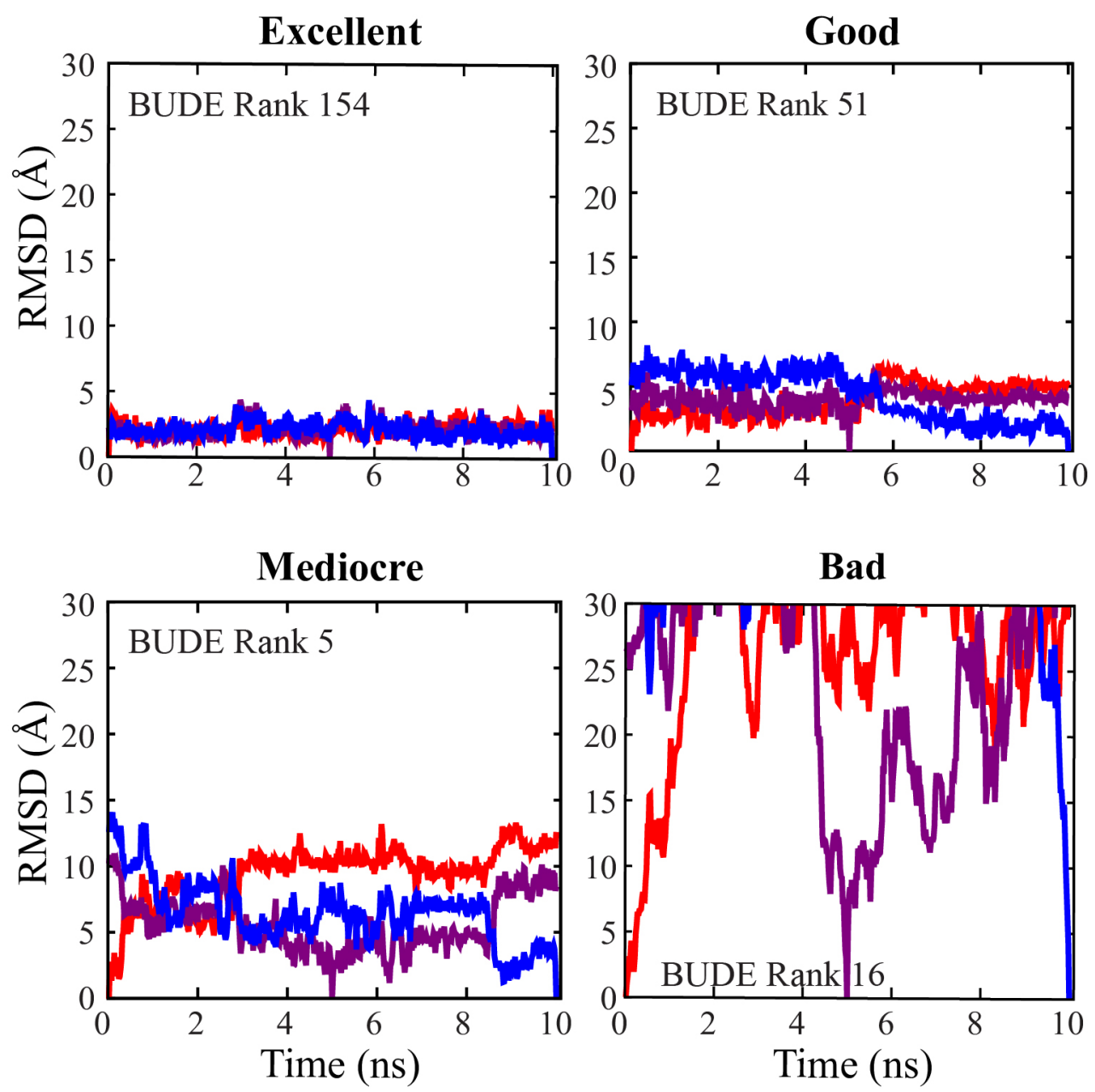

RMSD compared to initial pose RMSD compared to mid-point pose

RMSD compared to final pose

Figure 6. Coordinates of selected ligands over the course of $10 \mathrm{~ns}$ MD simulations were compared to the starting (red), midpoint (purple) and endpoint (blue). Ligands were deemed as "excellent" (low RMSDs), "good" (RMSDs $<10 \AA ̊$ ), "mediocre" (RMSDs > $10 \AA$ ) or "bad" (RMSDs > $30 \AA$, indicating dissociation). 

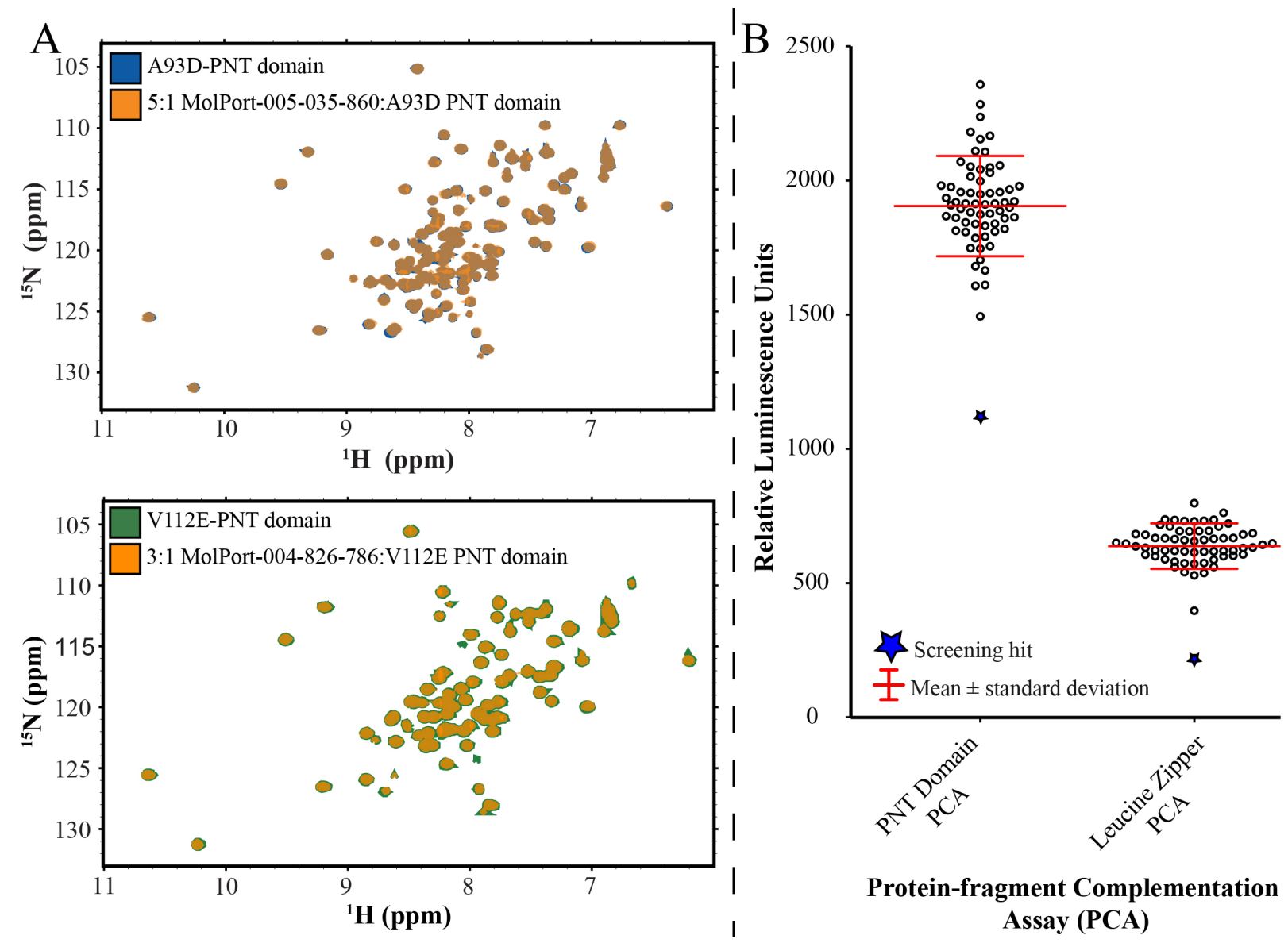

Protein-fragment Complementation Assay (PCA)

Figure 7. (A) Shown are overlaid ${ }^{15} \mathrm{~N}-\mathrm{HSQC}$ spectra of the ${ }^{15} \mathrm{~N}$-labelled A93D-ETV6 $63-125$ in the absence (blue) and presence of a 5:1 molar ratio (orange) of a BUDE screening hit MolPort-005035-860 (top), and the ${ }^{15} \mathrm{~N}-$ labelled V112E-ETV6 $6^{43-125}$ in the absence (green) and presence of a 3:1 molar ratio (orange) of a BUDE screening hit MolPort-004-826-786 (bottom). The lack of any amide chemical shift perturbations indicated no detectable binding. (B) Luminescence readings of 60 compounds, identified through the BUDE virtual screens, tested with the mammalian cell split luciferase assay. One compound (MolPort-005-970-014; blue star), reduced luminescence in both the PNT domain and leucine zipper PCAs. The lower signals relative to previously presented studies is due to the use of a BioTek Neo 2 plate reader. 


\title{
$\underline{\text { Supplemental Material }}$
}

\section{A Multi-pronged Screening Approach Targeting Inhibition of ETV6 PNT Domain Polymerization}

\author{
Chloe A. N. Gerak ${ }^{1}$, Si Miao Zhang ${ }^{1}$, Aruna Balgi ${ }^{1}$, Ivan Sadowski ${ }^{1}$, \\ Richard B. Sessions ${ }^{2}$, Lawrence P. McIntosh ${ }^{1,3}$, Michel Roberge ${ }^{1}$
}

${ }^{1}$ Department of Biochemistry and Molecular Biology, University of British Columbia, Vancouver, BC, Canada

${ }^{2}$ School of Biochemistry, University of Bristol, Bristol, United Kingdom

${ }^{3}$ Department of Chemistry, University of British Columbia, Vancouver, BC, Canada

Corresponding Author Michel Roberge, Department of Biochemistry and Molecular Biology, University of British Columbia, Vancouver, BC, Canada.

Email: michelr@mail.ubc.ca 
Supplemental Table S1. Protein sequences of selected PCA constructs

\begin{tabular}{|c|c|}
\hline Description & Sequence \\
\hline $\begin{array}{l}\qquad \text { Zip/N-Luc } \\
\text { GCN4 leucine zipper (blue), joined by a linker } \\
\text { (purple) to the N-terminal fragment of humanized } \\
\text { Gaussia luciferase (hGLuc(1) })^{1-93} \text {; orange). }\end{array}$ & $\begin{array}{l}\text { MNTEAARRSRARKLQRMKQLEDK } \\
\text { VEELLSKNYHLENEVARLKKLVGE } \\
\text { RIDGGGGSGGGGSSGKPTENNEDF } \\
\text { NIVAVASNFATTDLDADRGKLPGK } \\
\text { KLPLEVLKEMEANARKAGCTRGCL } \\
\text { ICLSHIKCTPKMKKFIPGRCHTYEG } \\
\text { DKESAQGGIG }\end{array}$ \\
\hline $\begin{array}{l}\qquad \text { Zip/C-Luc } \\
\text { GCN4 leucine zipper (blue), joined by a linker } \\
\text { (purple) to the C-terminal fragment of humanized } \\
\text { Gaussia luciferase (hGLuc }(2)^{94-196} ; \text { red). }\end{array}$ & $\begin{array}{l}\text { MNTEAARRSRARKLQRMKQLEDK } \\
\text { VEELLSKNYHLENEVARLKKLVGE } \\
\text { RIDGGGGSGGGGSSGEAIVDIPEIPG } \\
\text { FKDLEPMEQFIAQVDLCVDCTTGC } \\
\text { LKGLANVQCSDLLKKWLPQRCATF } \\
\text { ASKIQGQVDKIKGAGGD }\end{array}$ \\
\hline $\begin{array}{l}\text { A93D-PNT/N-Luc } \\
\text { ETV6 }{ }^{43-125} \text { with the PNT domain (magenta) and } \\
\text { monomerizing A93D mutation (cyan highlight), } \\
\text { joined by a linker (purple) to the N-terminal } \\
\text { fragment of humanized Gaussia luciferase } \\
\text { (hGLuc }(1)^{1-93} \text {; orange). }\end{array}$ & $\begin{array}{l}\text { MEEDSIRLPAHLRLQPIYWSRDDV } \\
\text { AQWLKWAENEFSLRPIDSNTFEMN } \\
\text { GKDLLLLTKEDFRYRSPHSGDVLY } \\
\text { ELLQHILKQRKGGGGSGGGGSSGK } \\
\text { PTENNEDFNIVAVASNFATTDLDA } \\
\text { DRGKLPGKKLPLEVLKEMEANAR } \\
\text { KAGCTRGCLICLSHIKCTPKMKKFI } \\
\text { PGRCHTYEGDKESAQGGIG }\end{array}$ \\
\hline $\begin{array}{l}\text { V112E-PNT/C-Luc } \\
\text { ETV6 }{ }^{43-125} \text { with the PNT domain (magenta) and } \\
\text { monomerizing V112E mutation (green highlight), } \\
\text { joined by a linker (purple) to the C-terminal } \\
\text { fragment of humanized Gaussia luciferase } \\
\text { (hGLuc }(2)^{94-196} \text {; red). }\end{array}$ & $\begin{array}{l}\text { MEEDSIRLPAHLRLQPIYWSRDDV } \\
\text { AQWLKWAENEFSLRPIDSNTFEMN } \\
\text { GKALLLLTKEDFRYRSPHSGDELY } \\
\text { ELLQHILKQRKGGGGSGGGGSSGE } \\
\text { AIVDIPEIPGFKDLEPMEQFIAQVDL } \\
\text { CVDCTTGCLKGLANVQCSDLLKK } \\
\text { WLPQRCATFASKIQGQVDKIKGAG } \\
\text { GD }\end{array}$ \\
\hline
\end{tabular}


Supplemental Table S2. Luminescence readings of the PNT domain PCA from transiently transfected cells and from stable pooled transformants.

\begin{tabular}{|l|c|c|}
\hline \multicolumn{1}{|c|}{ Plasmid(s) Transfected or Conditions } & $\begin{array}{c}\text { Hours Post- } \\
\text { Transfection }\end{array}$ & $\begin{array}{c}\text { Luminescence } \\
\text { Reading }\end{array}$ \\
\hline DMEM, no HEK293 cells & 48 & 20 \\
\hline $\begin{array}{l}\text { HEK293 cells with a mock (no DNA) } \\
\text { transfection }\end{array}$ & 48 & 25 \\
\hline V112E-PNT/C-Luc & 48 & 670 \\
\hline V112E-PNT/C-Luc & 72 & 500 \\
\hline A93D-PNT/C-Luc & 48 & 450 \\
\hline A93D-PNT/N-Luc & 48 & 690 \\
\hline A93D-PNT/N-Luc and V112E-PNT/N-Luc & 48 & 70 \\
\hline A93D-PNT/N-Luc and A93D-PNT/C-Luc & 48 & 2500 \\
\hline A93D-PNT/C-Luc and V112E-PNT/N-Luc & 48 & 320,000 \\
\hline A93D-PNT/C-Luc and V112E-PNT/N-Luc & 72 & 165,000 \\
\hline A93D-PNT/N-Luc and V112E-PNT/C-Luc & 48 & 61,000 \\
\hline A93D-PNT/N-Luc and V112E-PNT/C-Luc & 72 & 68,000 \\
\hline Zip/N-Luc and Zip/C-Luc ${ }^{1}$ & 48 & 22,000 \\
\hline Zip/N-Luc and Zip/C-Luc ${ }^{1}$ & 72 & 14,000 \\
\hline Stably expressing PNT domain PCA & N/A & 1,020 \\
\hline Stably expressing leucine zipper PCA & N/A & \\
\hline
\end{tabular}

${ }^{1}$ Denoted as Zip-hGLuc(1)and Zip-hGLuc(2) in Remy, I. and Michnick, S.W. Nat. Methods 2006, 3 (12), 977-979. 
Supplemental Table S3. Purchased compounds tested for binding to the A93D- or V112E-PNT domain (in context of ETV6 ${ }^{43-125}$ ) NMR spectroscopy. None bound as evidenced by the lack of any detectable amide ${ }^{1} \mathrm{H}^{\mathrm{N}}-{ }^{15} \mathrm{~N}$ chemical shift perturbations.

\begin{tabular}{|c|c|c|c|c|}
\hline Compound Tested & $\begin{array}{c}\text { Screening } \\
\text { Assay }\end{array}$ & $\begin{array}{c}\text { BUDE Rank } \\
\text { (if applicable) }\end{array}$ & $\begin{array}{c}\text { Tested PNT } \\
\text { Domain }\end{array}$ & $\begin{array}{c}\text { Molar Ratios } \\
\text { Tested }\end{array}$ \\
\hline Merbromin & PNT PCA & & A93D & 3 \\
\hline Sarmentogenin & PNT PCA & & A93D & $0.5,5$ \\
\hline 4'-hydroxychalcone & PNT PCA & & A93D & $0.5,5$ \\
\hline Emetine dihydrochloride & PNT PCA & & A93D & 3 \\
\hline Cephaeline hydrochloride & PNT PCA & & A93D & $0.5,5$ \\
\hline Curcumin & PNT PCA & & A93D & $0.5,3$ \\
\hline N-oleoyldopamine & PNT PCA & & A93D & $0.5,3$ \\
\hline Lanatoside C & PNT PCA & & A93D & $0.5,5$ \\
\hline $\begin{array}{l}\text { N-p-tosyl-L-phenylalanine } \\
\text { chloromethyl ketone }\end{array}$ & PNT PCA & & A93D & $0.5,5$ \\
\hline Lasalocid A & PNT PCA & & A93D & $0.5,5$ \\
\hline Carnosic acid & PNT PCA & & A93D & $0.5,5$ \\
\hline Phorbadione & PNT PCA & & A93D & $0.5,2$ \\
\hline Oridonin & PNT PCA & & A93D & $0.5,5$ \\
\hline Paromomycin & Yeast 2-H & & $\begin{array}{l}\text { A93D, } \\
\text { V112E }\end{array}$ & $0.5,3$ \\
\hline Tannic Acid & Yeast 2-H & & $\begin{array}{l}\text { A93D, } \\
\text { V112E }\end{array}$ & $0.5,5$ \\
\hline Sanguinarine & Yeast 2-H & & $\begin{array}{l}\text { A93D, } \\
\text { V112E }\end{array}$ & $0.5,5$ \\
\hline MolPort-010-780-927 & $\begin{array}{l}\text { BUDE } \\
\text { (interface) }\end{array}$ & 6 & A93D & $0.5,5,20$ \\
\hline MolPort-005-019-637 & $\begin{array}{l}\text { BUDE } \\
\text { (interface) }\end{array}$ & 11 & A93D & 3 \\
\hline MolPort-007-725-254 & $\begin{array}{l}\text { BUDE } \\
\text { (interface) }\end{array}$ & 28 & A93D & 3 \\
\hline MolPort-007-701-986 & $\begin{array}{l}\text { BUDE } \\
\text { (interface) }\end{array}$ & 39 & A93D & 3 \\
\hline MolPort-005-140-761 & $\begin{array}{l}\text { BUDE } \\
\text { (interface) }\end{array}$ & 51 & A93D & $0.5,5$ \\
\hline MolPort-002-668-848 & $\begin{array}{l}\text { BUDE } \\
\text { (interface) }\end{array}$ & 56 & A93D & 5 \\
\hline MolPort-005-090-877 & $\begin{array}{l}\text { BUDE } \\
\text { (interface) }\end{array}$ & 78 & A93D & $0.5,5$ \\
\hline MolPort-005-123-375 & $\begin{array}{l}\text { BUDE } \\
\text { (interface) }\end{array}$ & 86 & A93D & $0.5,5$ \\
\hline MolPort-005-308-219 & $\begin{array}{l}\text { BUDE } \\
\text { (interface) }\end{array}$ & 93 & A93D & 3 \\
\hline
\end{tabular}




\begin{tabular}{|c|c|c|c|c|}
\hline Compound Tested & $\begin{array}{c}\text { Screening } \\
\text { Assay }\end{array}$ & $\begin{array}{c}\text { BUDE Rank } \\
\text { (if applicable) }\end{array}$ & $\begin{array}{c}\text { Tested PNT } \\
\text { Domain }\end{array}$ & $\begin{array}{c}\text { Molar Ratios } \\
\text { Tested }\end{array}$ \\
\hline MolPort-007-773-309 & $\begin{array}{l}\text { BUDE } \\
\text { (interface) }\end{array}$ & 95 & A93D & 3 \\
\hline MolPort-007-690-631 & $\begin{array}{l}\text { BUDE } \\
\text { (interface) }\end{array}$ & 129 & A93D & 3 \\
\hline MolPort-007-702-123 & $\begin{array}{l}\text { BUDE } \\
\text { (interface) }\end{array}$ & 130 & A93D & 3 \\
\hline MolPort-007-899-016 & $\begin{array}{l}\text { BUDE } \\
\text { (interface) }\end{array}$ & 155 & A93D & 3 \\
\hline MolPort-002-736-787 & $\begin{array}{l}\text { BUDE } \\
\text { (interface) }\end{array}$ & 208 & A93D & 3 \\
\hline MolPort-001-906-708 & $\begin{array}{l}\text { BUDE } \\
\text { (interface) }\end{array}$ & 255 & A93D & 3 \\
\hline MolPort-009-154-411 & $\begin{array}{l}\text { BUDE } \\
\text { (interface) }\end{array}$ & 292 & A93D & $0.5,5$ \\
\hline MolPort-009-723-175 & $\begin{array}{l}\text { BUDE } \\
\text { (interface) }\end{array}$ & 319 & A93D & 5 \\
\hline MolPort-005-299-926 & $\begin{array}{l}\text { BUDE } \\
\text { (interface) }\end{array}$ & 374 & A93D & $0.5,5$ \\
\hline MolPort-005-689-600 & $\begin{array}{l}\text { BUDE } \\
\text { (interface) }\end{array}$ & 378 & A93D & $0.5,5$ \\
\hline MolPort-009-483-070 & $\begin{array}{l}\text { BUDE } \\
\text { (interface) }\end{array}$ & 421 & A93D & $0.5,5,20$ \\
\hline MolPort-009-178-639 & $\begin{array}{l}\text { BUDE } \\
\text { (interface) }\end{array}$ & 428 & A93D & $0.5,5$ \\
\hline MolPort-009-077-356 & $\begin{array}{l}\text { BUDE } \\
\text { (interface) }\end{array}$ & 453 & A93D & 3 \\
\hline MolPort-005-035-860 & $\begin{array}{l}\text { BUDE } \\
\text { (interface) }\end{array}$ & 466 & A93D & $0.5,5$ \\
\hline MolPort-009-113-626 & $\begin{array}{l}\text { BUDE } \\
\text { (interface) }\end{array}$ & 478 & A93D & $0.5,5,20$ \\
\hline MolPort-001-930-558 & $\begin{array}{l}\text { BUDE } \\
\text { (interface) }\end{array}$ & 631 & A93D & 3 \\
\hline MolPort-001-930-557 & $\begin{array}{l}\text { BUDE } \\
\text { (interface) }\end{array}$ & 825 & A93D & 3 \\
\hline MolPort-000-512-139 & $\begin{array}{l}\text { BUDE } \\
\text { (interface) }\end{array}$ & 2585 & A93D & 3 \\
\hline MolPort-004-881-711 & $\begin{array}{l}\text { BUDE } \\
\text { (interface) }\end{array}$ & 3186 & A93D & 3 \\
\hline MolPort-004-284-939 & $\begin{array}{l}\text { BUDE } \\
\text { (interface) }\end{array}$ & 3584 & A93D & 3 \\
\hline MolPort-008-311-002 & $\begin{array}{l}\text { BUDE } \\
\text { (interface) }\end{array}$ & 4073 & A93D & 3 \\
\hline MolPort-007-566-792 & $\begin{array}{l}\text { BUDE } \\
\text { (interface) }\end{array}$ & 7648 & A93D & 3 \\
\hline
\end{tabular}




\begin{tabular}{|c|c|c|c|c|}
\hline Compound Tested & $\begin{array}{c}\text { Screening } \\
\text { Assay }\end{array}$ & $\begin{array}{c}\text { BUDE Rank } \\
\text { (if applicable) }\end{array}$ & $\begin{array}{c}\text { Tested PNT } \\
\text { Domain }\end{array}$ & $\begin{array}{c}\text { Molar Ratios } \\
\text { Tested }\end{array}$ \\
\hline MolPort-004-882-201 & $\begin{array}{l}\text { BUDE } \\
\text { (interface) }\end{array}$ & 7994 & A93D & 3 \\
\hline MolPort-003-155-823 & $\begin{array}{l}\text { BUDE } \\
\text { (interface) }\end{array}$ & 8088 & A93D & 3 \\
\hline MolPort-019-818-459 & $\begin{array}{l}\text { BUDE } \\
\text { (interface) }\end{array}$ & $\begin{array}{l}\text { N/A Structural } \\
\text { Analog }\end{array}$ & A93D & 3 \\
\hline MolPort-007-690-631 & $\begin{array}{l}\text { BUDE } \\
\text { (interface) }\end{array}$ & 2 & V112E & 3 \\
\hline MolPort-007-690-630 & $\begin{array}{l}\text { BUDE } \\
\text { (interface) }\end{array}$ & 3 & V112E & $0.5,5,22$ \\
\hline MolPort-005-970-014 & $\begin{array}{l}\text { BUDE } \\
\text { (interface) }\end{array}$ & 75 & V112E & $0.5,5$ \\
\hline MolPort-002-694-487 & $\begin{array}{l}\text { BUDE } \\
\text { (interface) }\end{array}$ & 76 & V112E & $0.5,5$ \\
\hline MolPort-001-020-317 & $\begin{array}{l}\text { BUDE } \\
\text { (interface) }\end{array}$ & 89 & V112E & $0.5,1,3,5,10$ \\
\hline MolPort-009-696-679 & $\begin{array}{l}\text { BUDE } \\
\text { (interface) }\end{array}$ & 92 & V112E & $0.5,5$ \\
\hline MolPort-000-473-014 & $\begin{array}{l}\text { BUDE } \\
\text { (interface) }\end{array}$ & 95 & V112E & 3 \\
\hline MolPort-009-746-988 & $\begin{array}{l}\text { BUDE } \\
\text { (interface) }\end{array}$ & 104 & V112E & $0.5,5,22$ \\
\hline MolPort-007-969-298 & $\begin{array}{l}\text { BUDE } \\
\text { (interface) }\end{array}$ & 129 & V112E & 3 \\
\hline MolPort-004-826-786 & $\begin{array}{l}\text { BUDE } \\
\text { (interface) }\end{array}$ & 134 & V112E & 3 \\
\hline MolPort-005-004-054 & $\begin{array}{l}\text { BUDE } \\
\text { (interface) }\end{array}$ & 136 & V112E & $0.5,5$ \\
\hline MolPort-044-259-270 & $\begin{array}{l}\text { BUDE } \\
\text { (interface) }\end{array}$ & 196 & V112E & $0.5,5$ \\
\hline MolPort-009-724-755 & $\begin{array}{l}\text { BUDE } \\
\text { (interface) }\end{array}$ & 253 & V112E & $0.5,5,20$ \\
\hline MolPort-002-736-787 & $\begin{array}{l}\text { BUDE } \\
\text { (interface) }\end{array}$ & 280 & V112E & 3 \\
\hline MolPort-003-175-993 & $\begin{array}{l}\text { BUDE } \\
\text { (interface) }\end{array}$ & 356 & V112E & $0.5,5$ \\
\hline MolPort-000-839-413 & $\begin{array}{l}\text { BUDE } \\
\text { (interface) }\end{array}$ & 376 & V112E & $0.5,5,20$ \\
\hline MolPort-002-571-074 & $\begin{array}{l}\text { BUDE } \\
\text { (interface) }\end{array}$ & 385 & V112E & 3 \\
\hline MolPort-003-109-637 & $\begin{array}{l}\text { BUDE } \\
\text { (interface) }\end{array}$ & 483 & V112E & $0.5,5$ \\
\hline MolPort-002-007-977 & $\begin{array}{l}\text { BUDE (salt } \\
\text { bridge) }\end{array}$ & 31 & A93D & 3 \\
\hline
\end{tabular}




\begin{tabular}{|l|l|l|l|l|}
\hline \multicolumn{1}{|c|}{ Compound Tested } & $\begin{array}{l}\text { Screening } \\
\text { Assay }\end{array}$ & $\begin{array}{c}\text { BUDE Rank } \\
\text { (if applicable) }\end{array}$ & $\begin{array}{c}\text { Tested PNT } \\
\text { Domain }\end{array}$ & $\begin{array}{c}\text { Molar Ratios } \\
\text { Tested }\end{array}$ \\
\hline MolPort-005-102-430 & $\begin{array}{l}\text { BUDE (salt } \\
\text { bridge) }\end{array}$ & 43 & A93D & 3 \\
\hline MolPort-002-668-848 & $\begin{array}{l}\text { BUDE (salt } \\
\text { bridge) }\end{array}$ & 2860 & A93D & 3 \\
\hline MolPort-009-704-070 & $\begin{array}{l}\text { BUDE (salt } \\
\text { bridge) }\end{array}$ & 3221 & A93D & 3 \\
\hline MolPort-009-747-005 & $\begin{array}{l}\text { BUDE (salt } \\
\text { bridge) }\end{array}$ & 1 & V112E & 3 \\
\hline MolPort-009-746-988 & $\begin{array}{l}\text { BUDE (salt } \\
\text { bridge) }\end{array}$ & 3 & V112E & 3 \\
\hline MolPort-003-156-017 & $\begin{array}{l}\text { BUDE (salt } \\
\text { bridge) }\end{array}$ & 22 & V112E & 3 \\
\hline MolPort-009-747-002 & $\begin{array}{l}\text { BUDE (salt } \\
\text { bridge) }\end{array}$ & 45 & V112E & 3 \\
\hline MolPort-001-630-482 & $\begin{array}{l}\text { BUDE (salt } \\
\text { bridge) }\end{array}$ & 75 & V112E & 3 \\
\hline MolPort-008-295-789 & $\begin{array}{l}\text { BUDE (salt } \\
\text { bridge) }\end{array}$ & 3580 & 3 \\
\hline
\end{tabular}


A

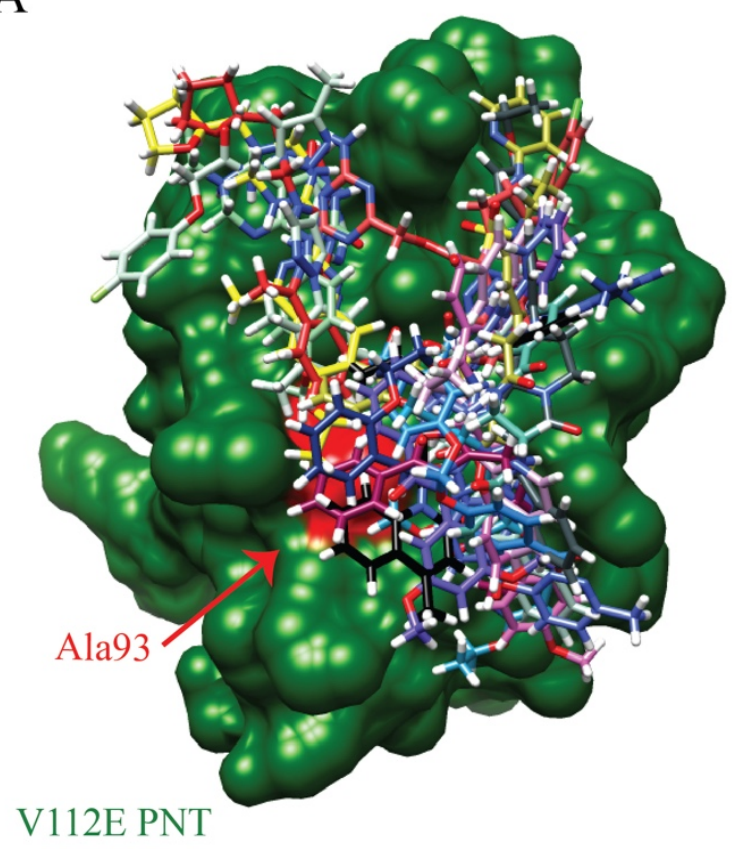

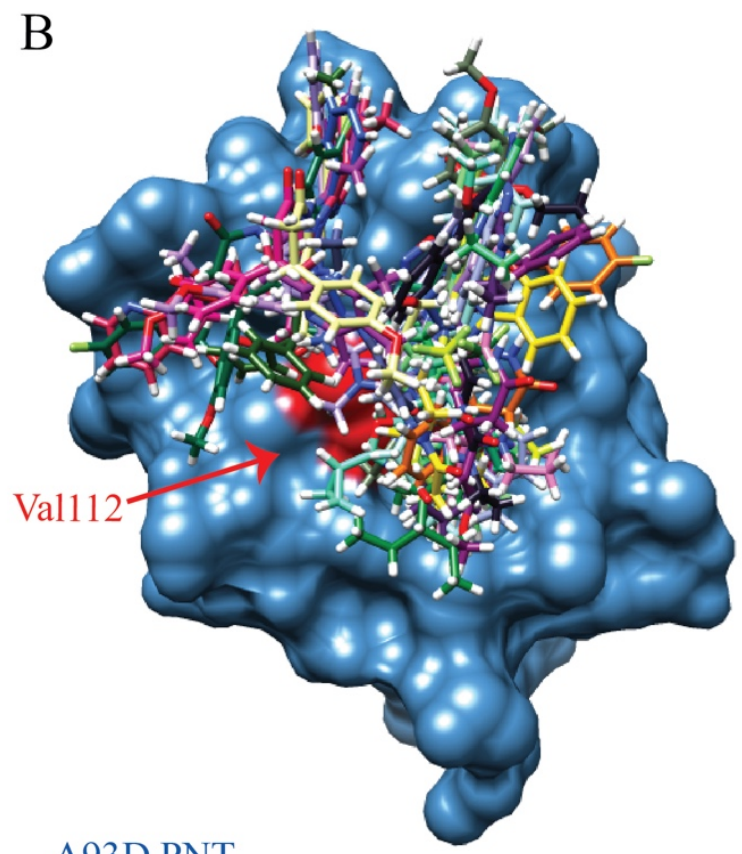

A93D PNT

Supplemental Figure S1. The BUDE compounds tested for binding at the interface and their predicted binding site. (A) Rendition of the V112E-PNT domain with compounds predicted to bind the ML surface centered around A93 (red). (B) Rendition of the A93D-PNT domain with compounds predicted to bind the EH surface centered around V112 (red). A range of binding locations can be seen. The protein structures were adapted from PDB 1LKY. The superimposed docked compounds are shown in stick format (hydrogen, white; nitrogen, blue; oxygen, red; sulfur, yellow; halogens, neon green; carbon, remaining colors). 

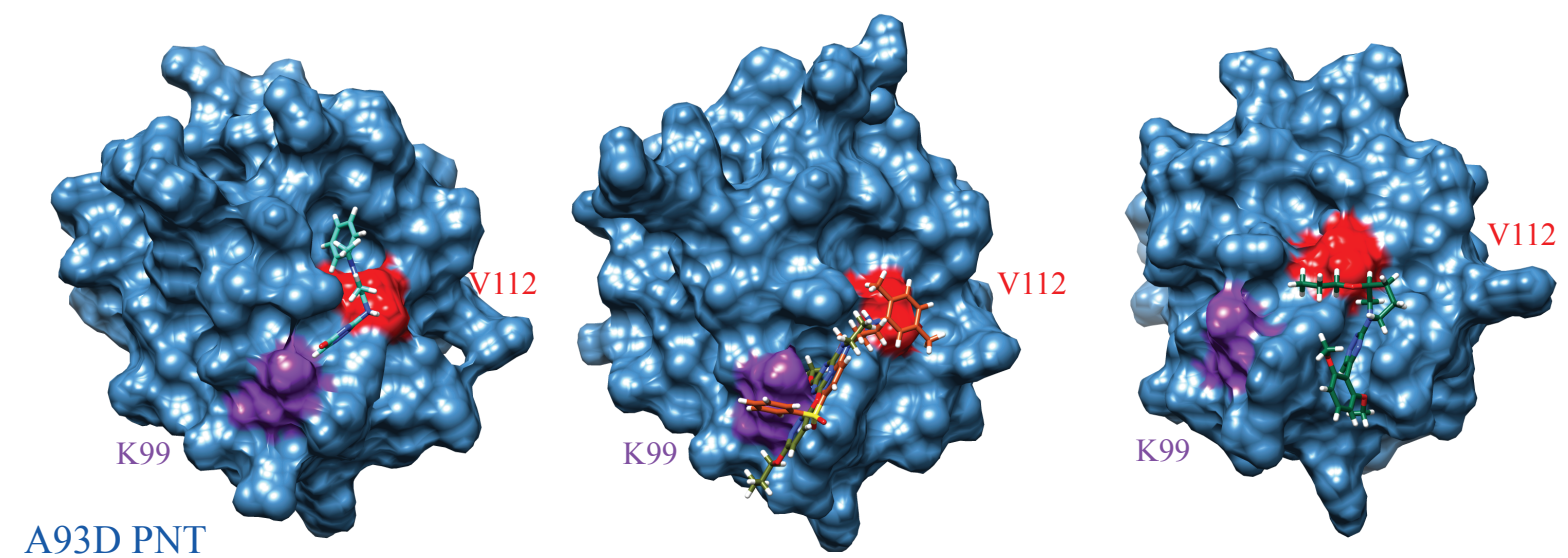

V112E PNT
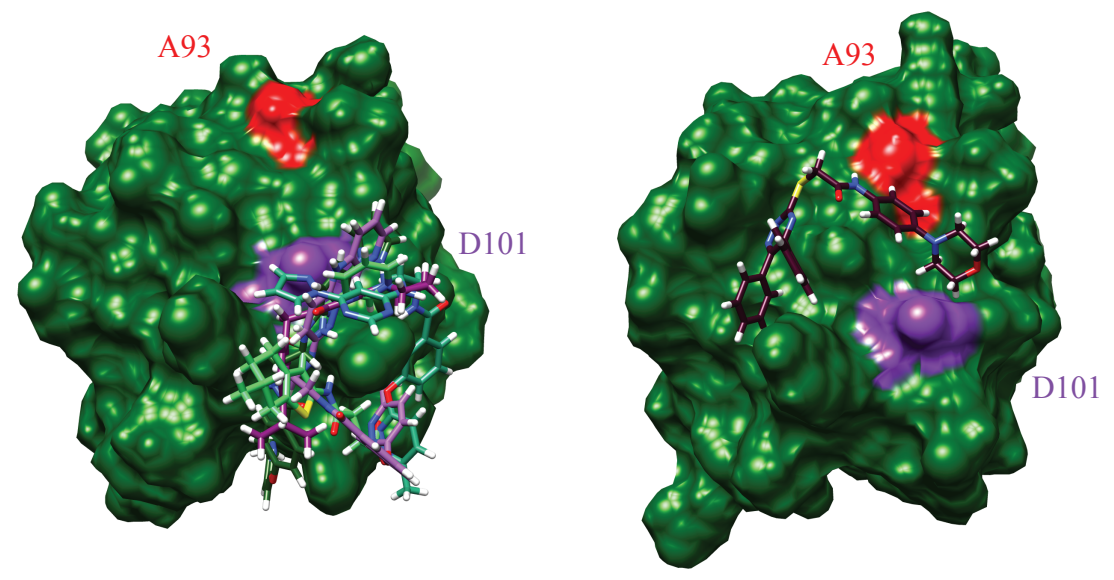

Val112 or Ala93

Lys99 or Asp101

Supplemental Figure S2. Virtual docking of compounds targeted to the K99-D101 interfacial regions of the PNT domain. Shown are surface models of three A93D PNT domain (blue) and two V112E PNT domain (green) structures, generated by MD simulations, with four and six docked compounds, respectively, that were experimentally tested for binding by NMR spectroscopy. The superimposed docked compounds are shown in stick format (hydrogen, white; nitrogen, blue; oxygen, red; sulfur, yellow; halogens, neon green; carbon, remaining colors). 